Research paper

\title{
CRN2 binds to TIMP4 and MMP14 and promotes perivascular invasion of glioblastoma cells
}

\author{
Roxana Solga $^{\mathrm{a}}$, Juliane Behrens ${ }^{\mathrm{a}}$, Anja Ziemann ${ }^{\mathrm{a}}$, Adrien Riou ${ }^{\mathrm{b}}$, Carolin Berwanger ${ }^{\mathrm{a}, \mathrm{c}}$, \\ Lore Becker $^{\mathrm{d}}$, Lillian Garrett ${ }^{\mathrm{d}, \mathrm{e}}$, Martin Hrabe de Angelis ${ }^{\mathrm{d}, \mathrm{f}, \mathrm{g}}$, Lisa Fischer ${ }^{\mathrm{h}}$, Roland Coras ${ }^{\mathrm{i}}$, \\ Katalin Barkovits ${ }^{j}$, Katrin Marcus ${ }^{j}$, Esther Mahabir ${ }^{h}$, Ludwig Eichinger ${ }^{\mathrm{a}}$, Rolf Schröder ${ }^{\mathrm{i}}$, \\ Angelika A. Noegel ${ }^{a, *}$, Christoph S. Clemen ${ }^{a, i, k, *}$, The German Mouse Clinic Consortium ${ }^{1}$ \\ ${ }^{\text {a }}$ Centre for Biochemistry, Institute of Biochemistry I, Medical Faculty, University of Cologne, 50931, Cologne, Germany \\ ${ }^{\mathrm{b}}$ In-vivo NMR, Max Planck Institute for Metabolism Research, 50931, Cologne, Germany \\ ${ }^{\mathrm{c}}$ Institute of Aerospace Medicine, German Aerospace Center (DLR), 51147, Cologne, Germany \\ ${ }^{\mathrm{d}}$ German Mouse Clinic, Institute of Experimental Genetics, Helmholtz Centre Munich, German Research Centre for Environmental Health, 85764, Neuherberg, Germany \\ e Institute of Developmental Genetics, Helmholtz Zentrum München, German Research Center for Environmental Health, 85764, Neuherberg, Germany \\ ${ }^{\mathrm{f}}$ Chair of Experimental Genetics, School of Life Science Weihenstephan, Technische Universität München, 85354, Freising, Germany \\ ${ }^{\mathrm{g}}$ German Center for Diabetes Research (DZD), 85764, Neuherberg, Germany \\ ${ }^{\mathrm{h}}$ Comparative Medicine, Center for Molecular Medicine Cologne, University of Cologne, 50931, Cologne, Germany \\ ${ }^{\mathrm{i}}$ Institute of Neuropathology, University Hospital Erlangen, Friedrich-Alexander University Erlangen-Nürnberg, 91054, Erlangen, Germany \\ ${ }^{\mathrm{j}}$ Medizinisches Proteom-Center, Medical Faculty, Ruhr-University Bochum, 44801, Bochum, Germany \\ ${ }^{\mathrm{k}}$ Center for Physiology and Pathophysiology, Institute of Vegetative Physiology, Medical Faculty, University of Cologne, 50931, Cologne, Germany
}

A R T I C L E IN F O

\section{Keywords:}

Coronin

Metalloproteinases

Glioblastoma

Mouse model

Cancer

Invasion

\begin{abstract}
A B S T R A C T
CRN2 is an actin filament binding protein involved in the regulation of various cellular processes including cell migration and invasion. CRN2 has been implicated in the malignant progression of different types of human cancer. We used CRN2 knock-out mice for analyses as well as for crossbreeding with a Tp53/Pten knock-out glioblastoma mouse model. CRN2 knock-out mice were subjected to a phenotyping screen at the German Mouse Clinic. Murine glioblastoma tissue specimens as well as cultured murine brain slices and glioblastoma cell lines were investigated by immunohistochemistry, immunofluorescence, and cell biological experiments. Protein interactions were studied by immunoprecipitation, pull-down, and enzyme activity assays. CRN2 knock-out mice displayed neurological and behavioural alterations, e.g. reduced hearing sensitivity, reduced acoustic startle response, hypoactivity, and less frequent urination. While glioblastoma mice with or without the additional CRN2 knock-out allele exhibited no significant difference in their survival rates, the increased levels of CRN2 in transplanted glioblastoma cells caused a higher tumour cell encasement of murine brain slice capillaries. We identified two important factors of the tumour microenvironment, the tissue inhibitor of matrix metalloproteinase 4 (TIMP4) and the matrix metalloproteinase 14 (MMP14, synonym: MT1-MMP), as novel binding partners of CRN2. All three proteins mutually interacted and co-localised at the front of lamellipodia, and CRN2 was newly detected in exosomes. On the functional level, we demonstrate that CRN2 increased the secretion of TIMP4 as well as the catalytic activity of MMP14. Our results imply that CRN2 represents a pro-invasive effector within the tumour cell microenvironment of glioblastoma multiforme.
\end{abstract}

\section{Introduction}

The coronin protein CRN2 (synonyms: coronin 1C, coronin 3, CRNN4) is a ubiquitously expressed member of the coronin family of proteins (Clemen et al., 2008), which belongs to the super family of eukaryotic-specific WD40-repeat domain proteins (Smith, 2008). Since the first description of a coronin protein in Dictyostelium discoideum (de Hostos et al., 1991), the coronin family of conserved actin cytoskeleton regulator proteins meanwhile has been studied in various model organisms. Phylogenetic analyses determined seventeen coronin

\footnotetext{
* Corresponding authors at: Institute of Biochemistry I, Medical Faculty, University of Cologne, Joseph-Stelzmann-Str. 52, 50931, Cologne, Germany.

E-mail addresses: noegel@uni-koeln.de (A.A. Noegel), christoph.clemen@uni-koeln.de (C.S. Clemen).

${ }^{1} \mathrm{~A}$ full list of authors and their affiliations is provided in the Appendix section.
} 
subfamilies including alternatively spliced forms of specific coronins, coronin gene duplications in certain phylogenetic branches, a subfamily of chimeric coronins, and the most well-known seven coronin paralogs in mammals (Eckert et al., 2011; Morgan and Fernandez, 2008; Xavier et al., 2008, 2009). The 474 amino acid coronin protein CRN2 with an apparent molecular mass of $57 \mathrm{kDa}$ harbours a basic N-terminal signature motif (Rybakin and Clemen, 2005) followed by seven WD40repeats which adopt the fold of a seven-bladed $\beta$-propeller (Appleton et al., 2006; McArdle and Hofmann, 2008), a linker domain, and a Cterminal coiled coil mediating trimerization (Kammerer et al., 2005; Spoerl et al., 2002).

CRN2 is present in the cytoplasm and enriched at actin filaments, lamellipodia and membrane ruffles (Spoerl et al., 2002). It plays a role in multiple, actin filament-dependent cellular functions like proliferation, migration, formation of cellular protrusions, endocytosis, and secretion (Rosentreter et al., 2007). CRN2 binds to actin filaments via different actin binding sites (Chan et al., 2012; Xavier et al., 2012). Its actin filament bundling, inhibition of actin polymerization, and Arp2/3 complex binding capacities are disabled by protein kinase CK2 dependent phosphorylation at serine residue 463 within the coiled coil region (Xavier et al., 2012). CRN2 function likely is also regulated by proteintyrosine phosphatase 1B (PTP1B), as tyrosine-phosphorylated CRN2 has been identified as a substrate of PTP1B (Mondol et al., 2014). In addition to its direct effects on actin filaments, CRN2 modifies the actin cytoskeleton in conjunction with small G-proteins. Binding of CRN2 to GDP-Rac1 and RCC2 leads to an enrichment of GTP-Rac1 at membrane protrusions via vesicular trafficking (Williamson et al., 2014, 2015), and its interaction with GDP-Rab27a increased its F-actin bundling activity associated with endocytosis of the insulin secretory membrane for recycling in pancreatic beta-cells (Kimura et al., 2010).

Several studies demonstrated an involvement of CRN2 in the progression of different forms of human cancer. For example, it was identified as a potential marker for melanoma progression, possibly via the Erk mitogen-activated protein kinase cascade (Roadcap et al., 2008; Shields et al., 2007). Similarly, a marked increase of CRN2 expression was reported in hepatocellular carcinoma cells giving rise to pulmonary metastases (Wu et al., 2010). CRN2 has also been reported to be associated with a poor prognosis of gastric cancer (Cheng et al., 2019) and to promote the metastatic behaviour of gastric cancer cells including their migration and invasion (Ren et al., 2012). Furthermore, immunohistochemistry studies revealed a strong expression of CRN2 in the majority of primary effusion lymphoma cells (Luan et al., 2010). Notably, the expression of CRN2 was reported to correlate with the malignant phenotype of diffuse gliomas (Thal et al., 2008). In this respect, CRN2 knock-down in U373 and A172 human glioblastoma cells led to reduced levels of cell proliferation, cell motility and invasion into the extracellular matrix as compared to control cells (Thal et al., 2008). In contrast, CRN2 overexpression as well as expression of a S463A phosphorylation-resistant CRN2 variant in U373 glioblastoma cells increased proliferation, matrix degradation and invasion but decreased adhesion and formation of invadopodia-like extensions (Ziemann et al., 2013).

\section{Materials and methods}

\subsection{Generation of CRN2 knock-out mice and crossbreeding with a glioblastoma mouse model}

Generation of CRN2 knock-out mice was performed according to (Behrens et al., 2016). Validation of the correct gene targeting event, the CRN2 knock-out at the mRNA level, and the lack of CRN2 protein isoforms (Xavier et al., 2009) as well as potential truncated protein species was done by Southern blotting and PCR genotyping, RT-PCR in conjunction with sequencing, and immunoblotting using several monoand polyclonal CRN2-specific antibodies, respectively (Fig. 1 and data not shown).
Cryopreserved mouse embryos of a glioblastoma mouse model (GBM) that expresses an inducible form of the Cre recombinase under the control of the astrocyte-specific glial fibrillary acidic protein (GFAPCreER) with additional floxed p53 (originally from Anton Berns, Netherlands Cancer Institute, Amsterdam, The Netherlands) and Pten (originally from Tak Mak, University Health Network, Toronto, Canada) genes were generously provided by Suzanne Baker (St. Jude Children's Research Hospital, Memphis, USA) (Chow et al., 2011, 2008). We revitalised this mouse strain and bred the mice to homozygosity for floxed p53 (p53-LoxP) and Pten (Pten-LoxP), and to heterozygosity for GFAP-CreER resulting in the GBM strain which we used for control. Subsequently, we crossbred the GBM strain with our conditional CRN2 knock-out mouse strain to obtain mice harbouring the heterozygous GFAP-CreER allele as well as the homozygous p53-LoxP, Pten-LoxP and CRN2-LoxP alleles. After postnatal day five to eleven, mice received on three consecutive days the synthetic oestrogen analogue tamoxifen (Sigma-Aldrich, T5648-1 G; dissolved at $20 \mathrm{mg} / \mathrm{ml}$ in corn oil, Sigma-Aldrich, C8267-500ML) via intraperitoneal injection (112 $\mu \mathrm{l}$ solution/10 g mouse) to selectively activate Cre recombinase in astrocytes and induce glioblastoma formation.

Mice were handled in accordance with the German Animal Welfare Act (Tierschutzgesetz) as well as the German Regulation for the protection of animals used for experimental purposes or other scientific purposes (Tierschutz-Versuchstierverordnung). All investigations were approved by the governmental office for animal care (Landesamt für Natur, Umwelt und Verbraucherschutz North Rhine-Westphalia (LANUV NRW), Recklinghausen, Germany (reference number 8.8750.10 .31 .09 .045 ) as well as by the responsible authority of the district government of Upper Bavaria, Germany.

\subsection{Phenotypic analysis in the German Mouse Clinic}

Homozygous CRN2 knock-out mice and wild-type control littermates were subjected to a systematic, comprehensive phenotyping screen at the German Mouse Clinic at the Helmholtz Zentrum München (http://www.mouseclinic.de) as described previously (Fuchs et al., 2018, 2011, 2012; Gailus-Durner et al., 2005). This screen covers a broad range of parameters in the areas of allergy, behaviour, cardiovascular function, clinical chemistry, dysmorphology, energy metabolism, eye analysis and vision, hematology, immunology, neurology, and pathology.

\subsection{Magnetic resonance imaging (MRI) for glioblastoma screening}

For detection of glioblastoma, T2-weighted images (RARE and MSME) were acquired on a 9.4 T Biospec 94/20 USR small animal system equipped with $740 \mathrm{~m} \mathrm{~T} / \mathrm{m}$ gradients and a dual resonator system (Bruker, Germany) composed of a transmit-only $1 \mathrm{H}$ quadrature resonator (active decoupled for Suc Coils, ID $72 \mathrm{~mm}$, OD $112 \mathrm{~mm}$ ) and a receive-only $1 \mathrm{H}$ Mouse head quadrature surface coil. Mice were kept under isoflurane anaesthesia in a mouse restrainer with monitoring of breathing and body temperature. Quantitative T2 maps were calculated using IDL (Interactive Data Language). After co-registration and brain extraction using FSL (FMRIB Software Library), T2 maps were processed using in-house macros with Image J. The brain glioblastoma segmentation was obtained in each axial slice by selecting high intensity pixels related to tumour using two thresholds followed by manual erasing of ventricles or non-brain related areas.

\subsection{CD31 stains of organotypic brain slice cultures}

Organotypic brain slice cultures were generated and U373 glioblastoma cells were transplanted according to our previously described method (Ziemann et al., 2013). In brief, brains of 9-12 days old C57BL/ $6 \mathrm{~N}$ mice were dissected, the frontal poles of the hemispheres and the cerebella removed, coronal slices of $350 \mu \mathrm{m}$ prepared in cold 
A

\section{CRN2 wild-type}

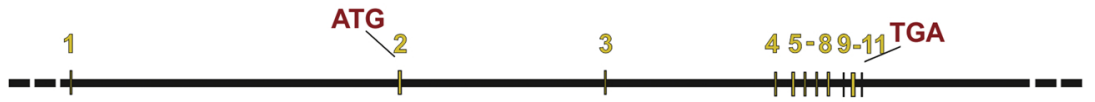

\section{CRN2 reporter insertion}

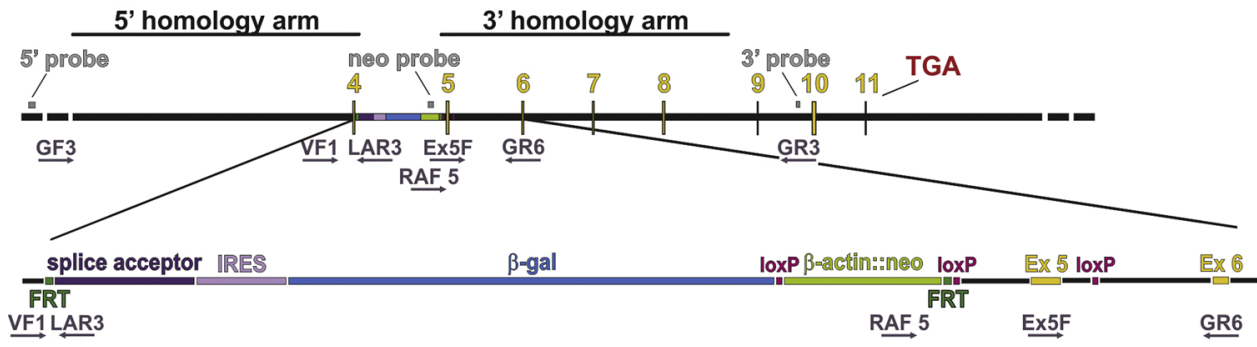

CRN2 conditional

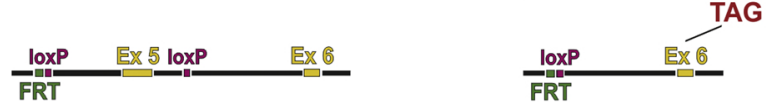

B
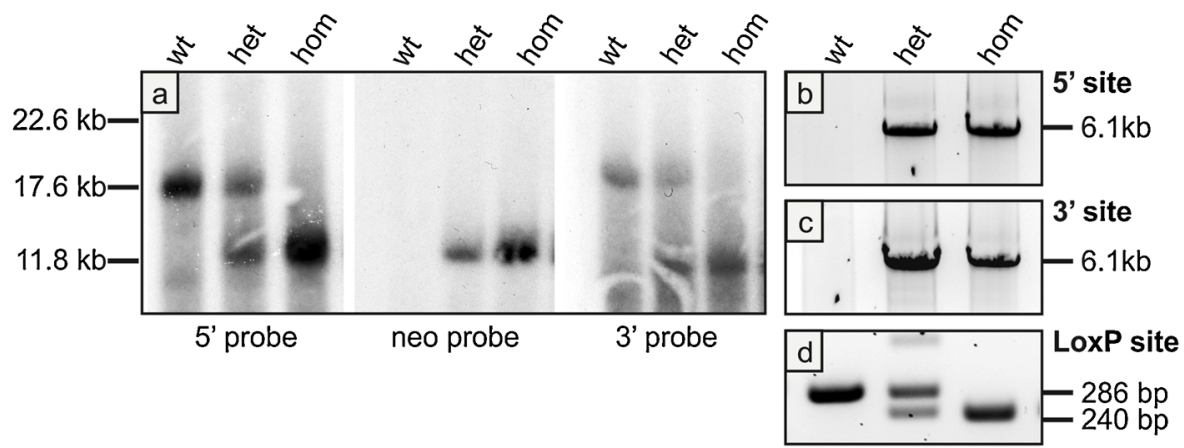

C

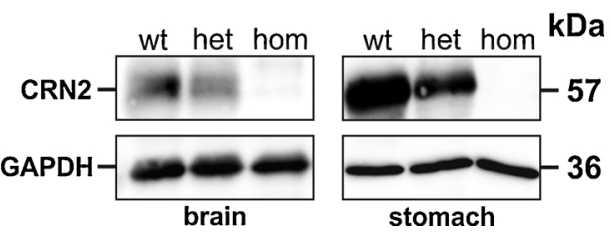

carbogenated glycerol-based modified artificial cerebrospinal fluid with a vibratome (Leica VT100S), the slices were immediately transferred into carbogenated preparation medium, and finally grown on porous tissue culture inserts in cultivation medium at $37{ }^{\circ} \mathrm{C}$ and $5 \% \mathrm{CO}_{2}$. The U373 human glioblastoma cells were transplanted on the entorhinal cortex after three days of culture and developed into tumours within two days.

For staining of endothelial cells, brain slices were washed with PBS and fixed with $4 \%$ paraformaldehyde in PBS for 30 min before washing again with PBS three times 15 min each. Subsequently, slices were incubated with PBS containing $2 \%$ Triton X-100 and $10 \%$ fetal calf serum for $30 \mathrm{~min}$. The primary antibodies directed against CD31 and GFP were diluted in $2 \%$ Triton X-100 and slices were incubated with antibodies overnight at room temperature (RT). Next, slices were washed three times $15 \mathrm{~min}$ each and incubated at RT for $2 \mathrm{~h}$ with the compatible secondary antibodies (coupled to DyLight550 and AlexaFluor488,
Fig. 1. CRN2 gene targeting approach and validation of the CRN2 knock-out allele. We generated CRN2 knock-out mice from two different ES cell clones, EPD0343_2_B04 and EPD0343_2_F09, which were obtained from the NCRR-NIH supported KOMP Repository (www. komp.org) and generated by the CSD consortium for the NIH funded Knockout Mouse Project (KOMP); see also (Behrens et al., 2016). CRN2 gene targeting was performed according to the "knockout first allele" strategy (Testa et al., 2004). (A) The CRN2 wild-type allele comprises 11 exons with an untranslated exon 1 , a start codon (ATG) in exon 2, and a stop codon (TGA) in exon 11. The CRN2 reporter insertion allele was generated by homologous recombination of the CRN2 targeting vector and consists of a $5^{\prime}$ flippase recognition target (FRT) site, a splice acceptor, an internal ribosome entry site (IRES), a $\beta$-gal reporter cassette, three locus of X-over P1 (loxP) sites flanking a neomycin selection cassette and exon 5, and another $3^{\prime}$ FRT site. Positions of the $5^{\prime}$-, neo-, and $3^{\prime}$-Southern blot probes as well as the PCR primers GF3, VF1, LAR3, RAF5, Ex5F, GR6, and GR3 are indicated. Removal of the $\beta$-gal reporter and neomycin selection cassettes by flippase (Flp)-mediated site-directed recombination results in the CRN2 conditional allele with the remaining, floxed (flanked by loxP) exon 5. Further cyclization recombination (Cre)-mediated deletion of exon 5 results in the CRN2 deletion allele causing a premature stop codon in exon 6 . The $5^{\prime}$ and $3^{\prime}$ homology arms of the targeting vector were derived from C57BL/6 $\mathrm{N}$ genomic DNA. (B) Validation of the reporter tagged insertion allele in heterozygous and homozygous CRN2 knock-out mice by Southern blotting of BglII restriction digested genomic DNA as well as PCR analyses for the presence of the $5^{\prime}$ (primer pair GF3/LAR3) and 3'-arms (RAF5/ GR3) and the loxP sites (Ex5F/GR6) of the targeting vector. (C) Immunoblotting verifies the lack of CRN2 in homozygous mice, and the presence of only one CRN2 allele resulted in a haploinsufficiency. Equal loading was confirmed using a GAPDH antibody. diluted in PBS). Finally, slices were washed five times $10 \mathrm{~min}$ each before analysing in PBS in $\mu$-dishes (Ibidi).

\subsection{Western blotting, immunofluorescence, immunohistochemistry, and antibodies}

For Western blotting, cell samples were lysed in SDS-PAGE sample buffer (50 mM Tris-HCl pH 6.8, 4\% 2-mercaptoethanol, 1\% SDS, $0.002 \%$ bromophenol blue, $8 \%$ glycerol (Laemmli, 1970)), separated by $10 \%$ or $12 \%$ SDS-PAGE, and transferred to $0.2 \mu \mathrm{m}$ Nitrocellulose Blotting Membrane (GE Healthcare Life Sciences, \#10600001) by the semidry method (Towbin et al., 1979). Membranes were blocked with Trisbuffered saline-Tween-20 (TBS-T) buffer ( $10 \mathrm{mM}$ Tris-HCl pH 8.0, $150 \mathrm{mM} \mathrm{NaCl}, 0.2 \%$ Tween-20) containing $5 \%$ milk powder. Primary antibodies were diluted in TBS-T buffer and incubated overnight; secondary antibodies coupled to horseradish peroxidase (POD) were 
diluted in TBS-T and incubated for $1 \mathrm{~h}$ at RT. Visualisation was done by enhanced chemiluminescence, and signals were monitored by classical photographic film exposure (Amersham Hyperfilm ECL, \#28906837).

For immunofluorescence imaging, cells grown on coated (with $5 \mu \mathrm{g}$ / $\mathrm{ml}$ vitronectin) or non-coated coverslips were first fixed at RT for 20 min in formaldehyde prepared from 4\% paraformaldehyde in PBS. For adhesion assay, cell suspension was seeded on vitronectin coated coverslips, incubated for $90 \mathrm{~min}$ at $37^{\circ} \mathrm{C}$ and washed once with PBS before fixation. Fixation was followed by permeabilisation of cells with $0.5 \%$ Triton-X-100 in PBS for 10 min. Residual formaldehyde was blocked by incubation of the fixed cells with $0.15 \%$ glycine in PBS for $10 \mathrm{~min}$. After three washing steps with PBS, blocking of non-specific binding sites was performed with $1 \%$ BSA in PBS for $1 \mathrm{~h}$ at RT. The primary antibody was diluted as recommended by the manufacturer in PBS containing $0.5 \% \mathrm{BSA}$, and cells were incubated for $1 \mathrm{~h}$ at RT or $4{ }^{\circ} \mathrm{C}$ overnight. Next, cells were washed with PBS, incubated at RT for $1 \mathrm{~h}$ with the compatible secondary antibody (coupled to AlexaFluor 488/ 568/647, diluted in PBS containing 0.5\% BSA), and nuclei were stained with DAPI or F-actin with TRITC-phalloidin. To double-stain endogenous levels of CRN2 and TIMP4, the antibody directed against TIMP4 was first masked using an AffiniPure Fab fragment goat antimouse $(\mathrm{H}+\mathrm{L}$ ) (Jackson ImmunoResearch, \#115-005-072) diluted as recommended before proceeding with the staining protocol. After additional washing steps in PBS, cells were rinsed once with $\mathrm{ddH}_{2} \mathrm{O}$ and embedded in Gelvatol before imaging.

For histochemistry and immunohistochemistry, murine brains were formalin fixed, cut into slabs of $3 \mathrm{~mm}$ thickness, and embedded in paraffin. Each embedded slab was further cut with a microtome (Microm, Heidelberg, Germany) at $3 \mu \mathrm{m}$ thickness and stained with haematoxylin and eosin (H\&E). Immunohistochemical stains were performed using an automated staining apparatus (Ventana Benchmark, Roche Diagnostics, Mannheim, Germany).

Primary antibodies used were: mouse monoclonal anti-CRN2, K6444-4 (Spoerl et al., 2002); mouse monoclonal anti-GFP, K3-184-2 (Noegel et al., 2004); rabbit polyclonal anti-GFP, A-6455 (Thermo Fisher Scientific); mouse monoclonal anti-TIMP4, SB30c (Novus Biologicals); rabbit monoclonal anti-MMP14, EP1264Y (Abcam, \#ab51074); mouse monoclonal anti-Integrin $\alpha v \beta 3$ (Merck-Millipore, \#MAB1976); rat monoclonal anti-CD31 (BD Pharmingen, \#550274); rabbit polyclonal anti-Hsp70 (R\&D systems, AF1663); mouse monoclonal anti-MAP-2 (supplied by Dr. B. Riederer). Secondary antibodies used were: anti-mouse/rabbit/chicken/rat coupled to AlexaFluor 488/ 568/647 (Invitrogen) or coupled to POD anti-mouse/rabbit (Sigma). Factin was stained with TRITC-phalloidin (Sigma, \#P1951) and nuclei with DAPI (Roth, \#6335.1).

\subsection{The luminescence-based mammalian interactome mapping (LUMIER) technique}

This method is based on a double- or triple-transfection with plasmids coding for the proteins of interest tagged with either Renilla luciferase, Firefly luciferase or Protein A. The original protocol of the LUMIER technique was modified and optimised as detailed in (Behrens et al., 2016; Clemen et al., 2015). For measurement of luciferase activity, first Firefly assay buffer (25 mM Tris- $\mathrm{HCl} \mathrm{pH} \mathrm{7.8,} 15 \mathrm{mM} \mathrm{MgSO}_{4}$, $4 \mathrm{mM}$ EGTA, $1 \mathrm{mM}$ ATP, $200 \mu \mathrm{M}$ AMP, $1 \mathrm{mM}$ DTT, $100 \mu \mathrm{M}$ Luciferin, final buffer $\mathrm{pH}$ adjusted to 7.8) was added and used for measurements of the luminescence signal intensities using an Infinite M1000 plate reader (Tecan) in luminescence acquisition mode with an integration time of $10 \mathrm{~s} /$ well and the filter "Lumi Green 1" (520-570 nm). Next, the Renilla assay buffer ( $300 \mathrm{mM} \mathrm{NaCl}, \mathrm{Na}_{2}$ EDTA pH 8.0, $60 \mathrm{mM} \mathrm{KH}_{2} \mathrm{PO}_{4}$ / $\mathrm{K}_{2} \mathrm{HPO}_{4} \mathrm{pH} 7.5,0.5 \mathrm{mg} / \mathrm{ml} \mathrm{BSA}, 2.5 \mu \mathrm{M}$ coelenterazine (dissolved in $\mathrm{MeOH}$ ), final buffer $\mathrm{pH}$ adjusted to 7.0) was added to the wells and again the luminescence was measured with an integration time of $10 \mathrm{~s} /$ well using the "Blue 1" (370-480 nm) bandpass filter.

\subsection{Purification of bacterially expressed fusion proteins and pull-down analysis}

For the generation of different TIMP4 and MMP14 GST-fusion constructs, appropriate coding sequences were PCR amplified and cloned into the expression vector pGEX-6P-1 using EcoRI and XhoI sites. Combinations of the following primers were used: N-TIMP4-for CGGAATTCGACTACAAAGACGATGACGATAAAGGAGGTAGCGGCGGG AGTTGCAGCTGCGCCCCGG, N-TIMP4-rev AAGGAAAAAAGCGGCCGC TCAGCCACAGTTCAGATGGTAGTG, C-TIMP4-for CGGAATTCGACTAC AAAGACGATGACGATAAAGGAGGTAGCGGCGGGAGTTGCCAAATCAC CACCTGCTAC, C-TIMP4-rev AAGGAAAAAAGCGGCCGCTCAGGGCTG AACGATGTCAACAAAC, ExCell-MMP14-for CGGAATTCGACTACAAAG ACGATGACGATAAAGGAGGTAGCGGCGGGAGTGCGCTCGCCTCCC TCG, ExCell-MMP14-rev AAGGAAAAAAGCGGCCGCTCAGGCAGCCGC GCTCACC, InCell-MMP14-for CGGAATTCGACTACAAAGACGATGACG ATAAAGGAGGTAGCGGCGGGAGTAGACGCCATGGGACCCCC, InCellMMP14-rev AAGGAAAAAAGCGGCCGCTCAGACCTTGTCCAGCAGGG AAC, ProP-MMP14-rev AAGGAAAAAAGCGGCCGCTCAGCGCTTCCTTC GAACATTGG, PepAct-MMP14-for CGGAATTCGACTACAAAGACGATG ACGATAAAGGAGGTAGCGGCGGGAGTTACGCCATCCAGGGTCTCAA ATG, PepAct-MMP14-rev AAGGAAAAAAGCGGCCGCTCAGGTAGTCCT GGGTTGAGGG, and Hem-MMP14-for CGGAATTCGACTACAAAGACG ATGACGATAAAGGAGGTAGCGGCGGGAGTTCCCGGCCTTCTGTTC CTG. ArcticExpress cells expressing the GST-fusion proteins were resuspended in lysis buffer (10 mM Tris- $\mathrm{HCl}$ pH 8.0, $50 \mathrm{mM} \mathrm{NaCl}, 1 \mathrm{mM}$ EDTA, $5 \mathrm{mM}$ DTT, $1 \mathrm{mM}$ benzamidine, $1 \mathrm{mM}$ PMSF, $1 \%$ sarcosyl, $100 \mu \mathrm{g} / \mathrm{ml}$ lysozyme), sheared by douncing, and the proteins were purified from the soluble fraction using Glutathione-Sepharose beads (Macherey-Nagel). For pull-down assays, the beads carrying bait proteins (GST-TIMP4 or MMP14 constructs) were incubated together with lysates (in $50 \mathrm{mM}$ Tris- $\mathrm{HCl} \mathrm{pH} 8.0,50 \mathrm{mM} \mathrm{NaCl}, 0.5 \%$ Triton X-100, $4 \mathrm{mM}$ DTT, 1x protease inhibitor cocktail (Sigma, \#P2714), 1x phosphatase inhibitor cocktail (Roche, \#04906845001)) of U373 glioblastoma cell stably expressing the prey proteins (GFP-CRN2, or GFP for control (Ziemann et al., 2013)). After an incubation time of $3 \mathrm{~h}$ at $4{ }^{\circ} \mathrm{C}$ on a rotator, beads were washed and boiled in SDS sample buffer, and protein samples were subjected to SDS-PAGE and Western blot analyses.

\subsection{Discontinuous sucrose gradient}

For cell fractionation, U373 glioblastoma cells were trypsinised, washed with PBS and resuspended in ice cold HEPES buffer $(10 \mathrm{mM}$ HEPES pH 7.4, 1 mM DTT, 0.5 mM PMSF, $2 \mathrm{mM}$ benzamidine, $1 \mathrm{x}$ protease inhibitor cocktail, $1 \mathrm{x}$ phosphatase inhibitor cocktail). Cells were gently homogenised by passages through a 22-gauge needle to avoid disruption of cellular organelles, the resulting suspension was centrifuged at $1,000 \mathrm{x} g$ for $10 \mathrm{~min}$ to remove unbroken cells and nuclei, and the procedure was repeated twice. The supernatants were pooled and applied on top of polypropylene tubes containing a gradient of sucrose in $0.9 \mathrm{ml}$ steps of the following concentrations (from top to bottom): $0.15 \mathrm{M}, 0.3 \mathrm{M}, 0.45 \mathrm{M}, 0.6 \mathrm{M}, 0.75 \mathrm{M}, 0.9 \mathrm{M}, 1.05 \mathrm{M}, 1.17 \mathrm{M}$, $1.32 \mathrm{M}, 1.47 \mathrm{M}$, and $2.49 \mathrm{M}$. Afterwards, the tubes were centrifuged in an ultracentrifuge with a SW41 swing-out rotor at 100,000x g and $4{ }^{\circ} \mathrm{C}$ for $20 \mathrm{~h}$. Analyses of sucrose layer samples were performed by Western blot analysis.

\subsection{TIMP4 ELISA}

To measure secreted amounts of TIMP4 protein, $2 \times 10^{5}$ U373 glioblastoma cells were seeded in 6 -well plates coated with $0.2 \%$ gelatine. After $24 \mathrm{~h}$ incubation at $37^{\circ} \mathrm{C}$ and $5 \% \mathrm{CO}_{2}$, the growth medium was collected and the TIMP4 protein concentrations were determined according to the protocol of the human TIMP4 ELISA Kit (RayBiotech, ELH-TIMP4-1). 


\begin{tabular}{|c|c|c|}
\hline screen & method/parameter & phenotype (hom CRN2 KO vs. wild-type) \\
\hline \multirow{2}{*}{ allergy } & Ig-ELISA & no significant/marked difference \\
\hline & transepidermal water loss & no significant/marked difference \\
\hline \multirow[b]{2}{*}{ behaviour } & open field & no significant/marked difference \\
\hline & acoustic startle \& prepulse inhibition (PPI) & $\begin{array}{c}\text { decreased startle reactivity, } p=0.014 \\
\text { unchanged PPI }\end{array}$ \\
\hline \multirow{2}{*}{ cardiovascular } & electrocardiogram & no significant/marked difference \\
\hline & echocardiography & no significant/marked difference \\
\hline \multirow{3}{*}{ clinical chemistry } & ALP & 141 vs. $134 \mathrm{U} / \mathrm{l}$ female, 97 vs. $81 \mathrm{U} / \mathrm{l}$ male, $p=0.03$ \\
\hline & other parameters from autoanalyzer & no significant/marked difference \\
\hline & glucose tolerance test & no significant/marked difference \\
\hline \multirow{3}{*}{ dysmorphology } & visual inspection & no significant/marked difference \\
\hline & X-ray & no significant/marked difference \\
\hline & dual-energy X-ray absorptiometry & no significant/marked difference \\
\hline \multirow{2}{*}{$\begin{array}{l}\text { energy } \\
\text { metabolism }\end{array}$} & indirect calorimetry & no significant/marked difference \\
\hline & qNMR & no significant/marked difference \\
\hline \multirow{4}{*}{ eye } & Scheimpflug imaging & no significant/marked difference \\
\hline & optical coherence tomography & no significant/marked difference \\
\hline & laser interference biometry & no significant/marked difference \\
\hline & virtual drum & no significant/marked difference \\
\hline \multirow{3}{*}{ hematology } & platelet counts & $\begin{array}{l}939 \text { vs. } 88710^{3} / \mathrm{mm}^{3} \text { female, } \\
1211 \text { vs. } 100010^{3} / \mathrm{mm}^{3} \text { male, } p=0.027\end{array}$ \\
\hline & platelet distribution width & $\begin{array}{c}5.57 \text { vs. } 5.35 \mathrm{fl} \text { female, } \\
5.27 \text { vs. } 5.12 \mathrm{fl} \text { male, } p=0.029\end{array}$ \\
\hline & other blood counts & no significant/marked difference \\
\hline \multirow{2}{*}{ immunology } & parameters from flow cytometry & no significant/marked difference \\
\hline & multiplex bead array & no significant/marked difference \\
\hline \multirow{5}{*}{ neurology } & modified SHIRPA & $\begin{array}{c}24 \text { vs. } 28 \text { LA female, } 21 \text { vs. } 72 \text { LA male, } p=0.003 \\
64 \% \text { vs. } 27 \% \text { urination event, } p=0.045\end{array}$ \\
\hline & grip strength & no significant/marked difference \\
\hline & rotarod & no significant/marked difference \\
\hline & auditory brain stem response (click ABR) & 40 vs. $30 \mathrm{~dB}$ female, 35 vs. $30 \mathrm{~dB}$ male, $p<0.001$ \\
\hline & nociception/hot plate & no significant/marked difference \\
\hline \multirow{3}{*}{ pathology } & macroscopy & no significant/marked difference \\
\hline & histology (all organs/tissues) & no significant/marked difference \\
\hline & histology 1 -year-old animals (all organs/tissues) & no significant/marked difference \\
\hline
\end{tabular}




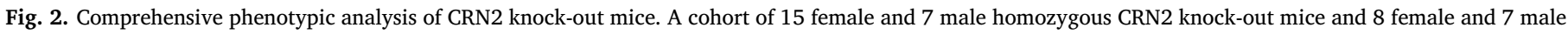

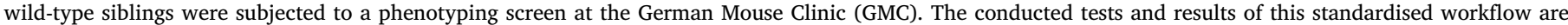

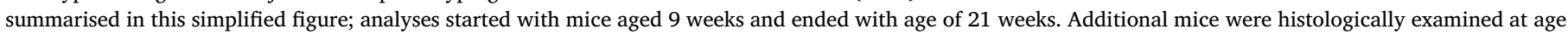

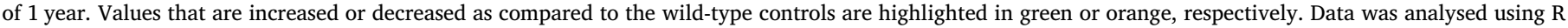

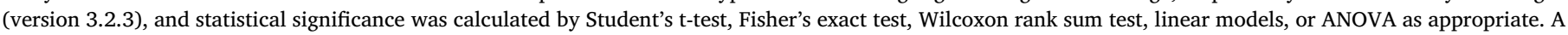

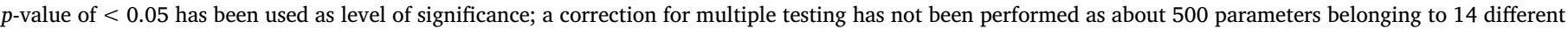

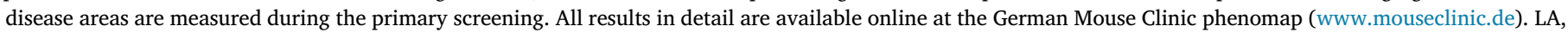
locomotor activity.

\subsection{MMP14 activity assay}

For measurement of MMP14 activity, GST-tagged MMP14 fusion proteins were used that were purified as described above. To determine a putative influence of CRN2 on MMP14 activity, U373 glioblastoma cells stably overexpressing GFP or GFP-CRN2 were resuspended in lysis buffer (see above), incubated for $30 \mathrm{~min}$ on ice and centrifuged for $15 \mathrm{~min}$ at $10,000 \mathrm{x} \mathrm{g}$ and $4{ }^{\circ} \mathrm{C}$. The supernatants were incubated with GFP-Trap beads (ChromoTek, Gta-10) to immunoprecipitate GFP-CRN2 or GFP for control according to the manufacturers' protocol. For the activity assay, GFP- or GFP-CRN2-carrying beads were mixed with GSTMMP14 construct-carrying beads, activity assay buffer ( $50 \mathrm{mM}$ Tris- $\mathrm{HCl}$ $\mathrm{pH} 7.5,150 \mathrm{mM} \mathrm{NaCl}, 10 \mathrm{mM} \mathrm{CaCl}_{2}, 0.05 \%$ Triton X-100) and $25 \mu \mathrm{m}$ OMNIMMP substrate (Enzo Life Science, BML-P126-0001). To inhibit MMP catalytic activity, $10 \mu \mathrm{M}$ NNGH (Enzo Life Science, BML-PI1150005) or vehicle (DMSO) were added to the samples, and kinetic measurements were performed every $2 \mathrm{~min}$ over $60 \mathrm{~min}$ at $37^{\circ} \mathrm{C}$ detecting fluorescence signal intensities using an Infinite M1000 plate reader (Tecan) at wavelengths of 328 and $393 \mathrm{~nm}$ for excitation and emission (bandwidth set to $10 \mathrm{~nm}$ for each), respectively.

\subsection{Purification of exosomes from cell culture supernatants}

For purification of exosomes according to (Redzic et al., 2014; Shin et al., 2013b), U373 glioblastoma cells stably expressing GFP-CRN2 were kept in serum-free medium for $48 \mathrm{~h}$, before supernatants were collected and centrifuged at $200 \mathrm{xg}$ and $4{ }^{\circ} \mathrm{C}$ for $5 \mathrm{~min}$ to eliminate cell debris. Supernatants were further cleared by centrifugation at 20,000 $\times \mathrm{g}$ and $4^{\circ} \mathrm{C}$ for $20 \mathrm{~min}$. Exosomes were pelleted from the latter supernatants by ultracentrifugation at $100,000 \times \mathrm{g}$ and $4^{\circ} \mathrm{C}$ for $16 \mathrm{~h}$ in a SW41 Ti (III) rotor (Beckman Coulter), followed by washing with PBS and another ultracentrifugation step at $100,000 \times \mathrm{g}$ and $4^{\circ} \mathrm{C}$ for $2.5 \mathrm{~h}$. The bottoms of the centrifugation tubes were incubated with SDS sample buffer to solubilize pelleted exosome fractions for analysis by SDS-PAGE. Total cell lysates were collected and used as a control.

\subsection{Confocal microscopy, image deconvolution, figure preparation, and data analysis}

All microscopic images were acquired with a TCS SP5 confocal laser scanning microscope equipped with HyD detectors (Leica, software LAS $\mathrm{AF}$ version 2.7.3.9723). Images were deconvolved using Huygens Essential (Jan 2016; Scientific Volume Imaging B.V.) as indicated in the figure legends. Images were processed and figures assembled using CorelDraw Graphics Suite X6 and X7.

Data analyses and statistical evaluations were carried out using Microsoft Excel 2010 or 2016 in conjunction with the add-in „Real Statistics Resource Pack" version 5.5 by Charles Zaiontz available at http://www.real-statistics.com as well as R (version 3.2.3). The number of independent experiments, technical replicates, mean values and standard errors are indicated in the figure legends. Statistical significance of the results was calculated by Student's t-test, the Lord-test (calculated according to (Kesel et al., 1999)), Fisher's exact test, Wilcoxon rank-sum test, the Kruskal-Wallis one-way analysis of variance in conjunction with posthoc Mann-Whitney U (Wilcoxon rank-sum) test, linear models, or ANOVA as appropriate and indicated in the figure legends.

\section{Results}

\subsection{Comprehensive phenotyping of CRN2 knock-out mice}

A cohort of 15 female and 7 male homozygous CRN2 knock-out mice (reporter insertion allele, Fig. 1A) and 8 female and 7 male wildtype siblings were subjected to a comprehensive phenotyping ("primary screen") at the German Mouse Clinic, Munich. Analyses started with mice aged 9 weeks and ended with age of 21 weeks. The conducted tests and results are summarised, and values that are increased or decreased as compared to the wild-type controls are highlighted in green or orange, respectively (Fig. 2). The analyses depicted neurological abnormalities, e.g. CRN2 knock-out mice needed higher sound pressure levels to respond to click and higher frequency tones indicating reduced hearing sensitivity. This correlates well with the reduced acoustic startle response detected in the behaviour screen. Furthermore, CRN2 knock-out mice were hypoactive and showed a slight reduction in urination frequency (modified SHIRPA). Moreover, several subtle phenotypic alterations were detected (echocardiography, clinical chemistry and haematology, immunology), which were predominantly sex-related. All results of the phenotypic screen in detail are available online at the German Mouse Clinic phenomap (www.mouseclinic.de). In addition, all organ systems of CRN2 knock-out mice also were histologically examined at the age of 1 year. Again, this analysis did not depict any obvious morphological alterations (Fig. 2).

\subsection{Glioblastoma formation in Tp53/Pten and Tp53/Pten/CRN2 knock- out mice}

To further analyse the effects of CRN2 in glioblastoma formation, we used a previously published glioblastoma model (Chow et al., 2011). The model expresses a tamoxifen-inducible form of the Cre recombinase under the control of the astrocyte-specific glial fibrillary acidic protein (GFAP-CreER) (Chow et al., 2008) into which we crossbred the conditional CRN2 knock-out allele (Fig. 1A). Crossbreeding resulted in mice harbouring the heterozygous GFAP-CreER allele as well as the homozygous Tp53-LoxP, Pten-LoxP and CRN2-LoxP alleles, thus enabling the combined deletion of Tp53, Pten and CRN2 in astrocytes. Out of a total number of $60 \mathrm{Tp} 53 /$ Pten (double) knock-out (glioblastoma model) and 47 Tp53/Pten/CRN2 (triple) knock-out (glioblastoma model with additional CRN2 allel) tamoxifen-injected and Cre-positive mice, brains of 14 Tp53/Pten knock-out and 24 Tp53/Pten/CRN2 knock-out mice were dissected for histopathological and biochemical analyses. Histopathological evaluation verified the presence of highly cellular, pleomorphic glioblastoma with abundant mitoses (arrows), pseudopalisading necrosis (asterisks) and thrombosed tumour vessels (arrowheads) in both genotypes (Fig. 3A,B,D,E). Immunoreactivity for microtubule-associated protein 2 (MAP-2), a protein associated with the neuronal cytoskeleton (Fig. 3J,K) that is established as a marker of glioblastoma cells (Blümcke et al., 2001), was detected in virtually all tumour cells (Fig. 3C,F). Further 15 Tp53/Pten knock-out and 8 Tp53/Pten/CRN2 knock-out mice were used for in vivo magnetic resonance imaging, which documented formation and rapid growth of glioblastoma (Fig. 3G,H). Due to differences in the time point of glioblastoma occurrence we were unable to make statistically reliable MRI analyses of the glioblastoma growth rates. However, a determination of the 
survival rates based on 38 Tp53/Pten knock-out and 30 Tp53/Pten/ CRN2 knock-out mice with tamoxifen-induced glioblastoma showed no clear differences between the genotypes (Fig. 3I).

\subsection{CRN2 enhances the perivascular invasion of glioblastoma cells}

To further explore the effect of CRN2 on the invasion of glioblastoma cells, we transplanted previously established U373 human glioblastoma cell lines (see Fig. 1 within reference (Ziemann et al., 2013)) onto the entorhinal cortex of murine coronal brain slices.
Subsequently, after two days of culture, confocal images were recorded with the immunostained CD31-positive capillaries (red) and the GFPfluorescence (green) of the GFP-CRN2 cells with stable overexpression of GFP-CRN2 in addition to the endogenous protein or CRN2-shRNA/ GFP cells with shRNA-mediated knock-down of the endogenous CRN2 in conjunction with expression of GFP. U373 cells only expressing GFP in addition to the endogenous CRN2 were included as a control. This assay allowed the quantitation of the number of capillaries encased by the glioblastoma cells (Fig. 4A). Notably, transplantation and invasion of the GFP-CRN2 expressing cells into the brain slice tissue led to a
A

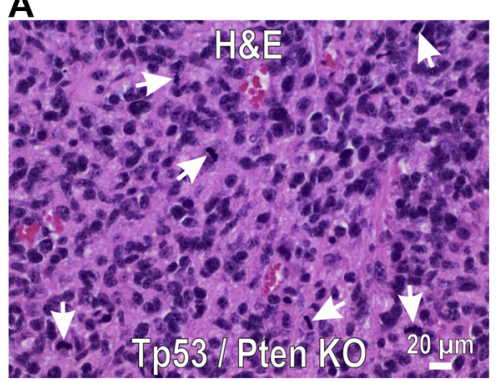

D

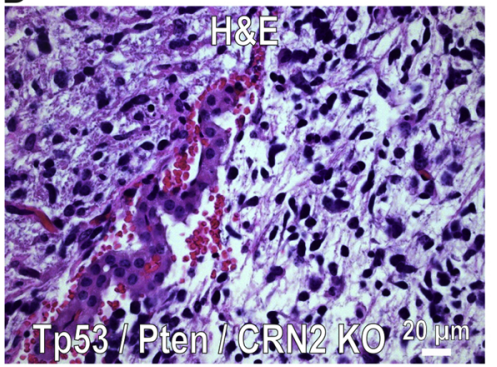

$\mathbf{G}$

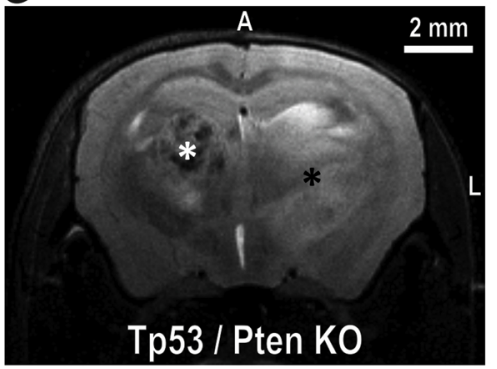

$J$

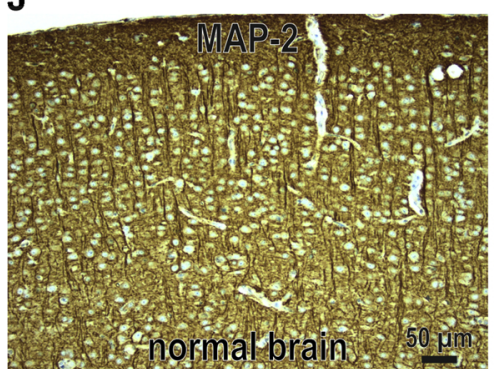

B

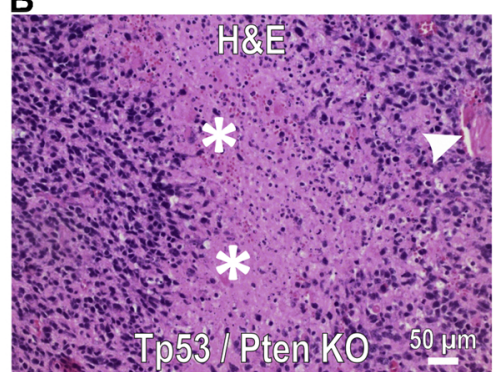

E

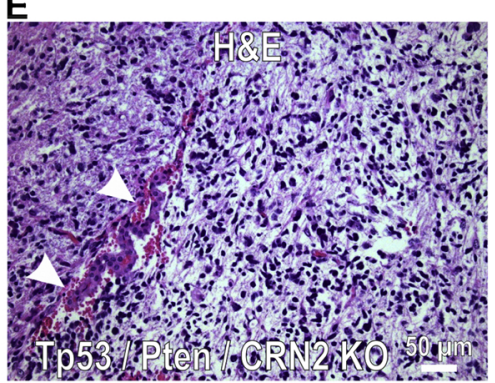

C

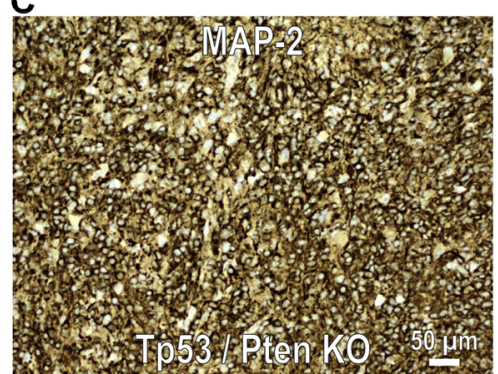

$F$

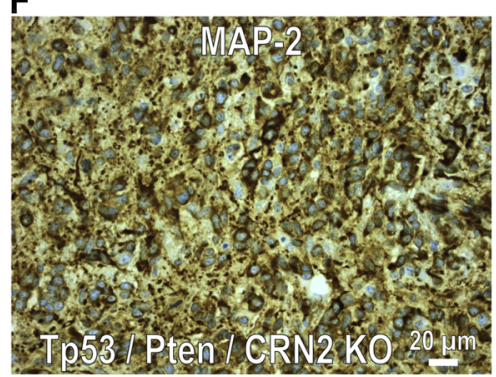

I

K
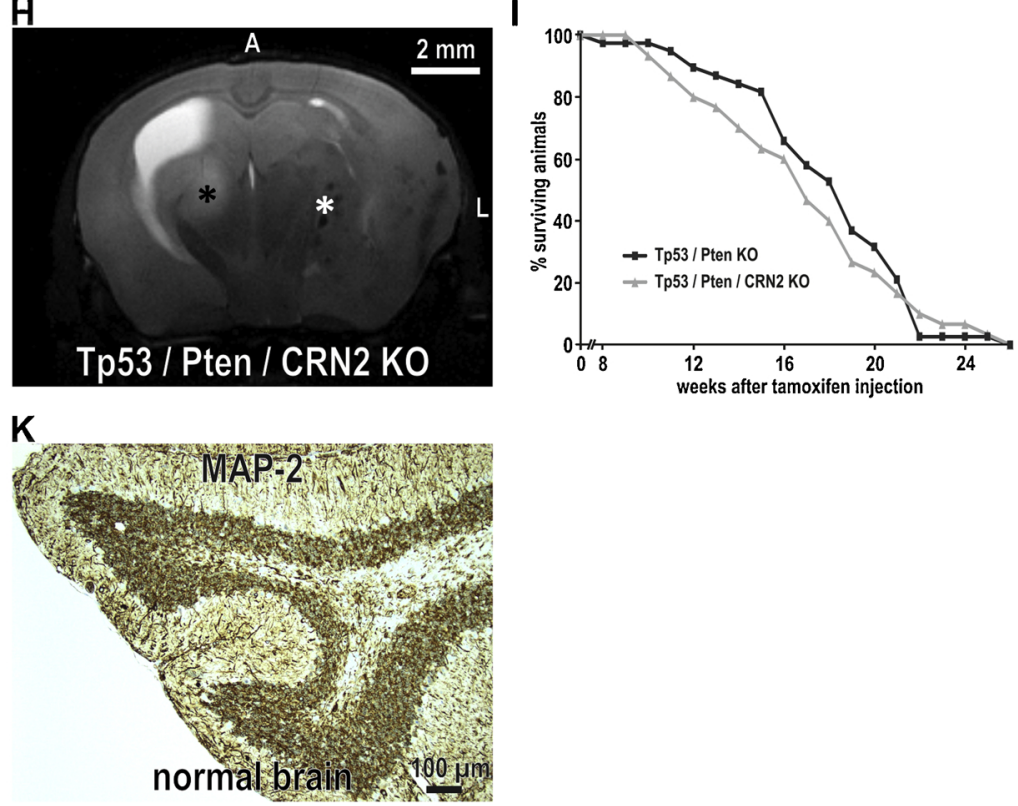

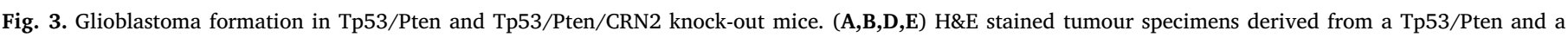

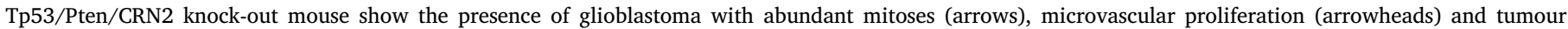

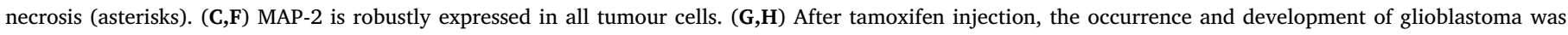

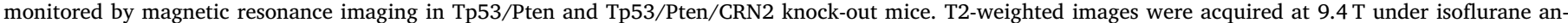

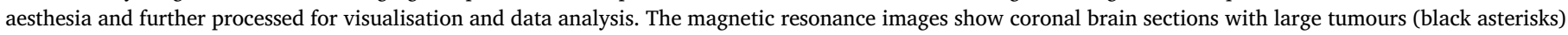

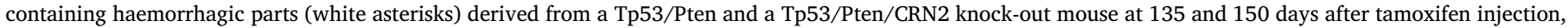

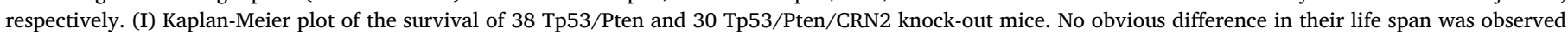

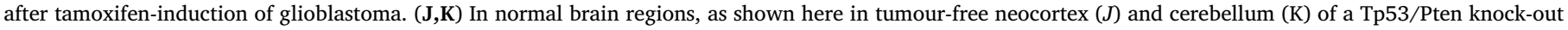
mouse, MAP-2 expression is basically limited to neurons. 
A

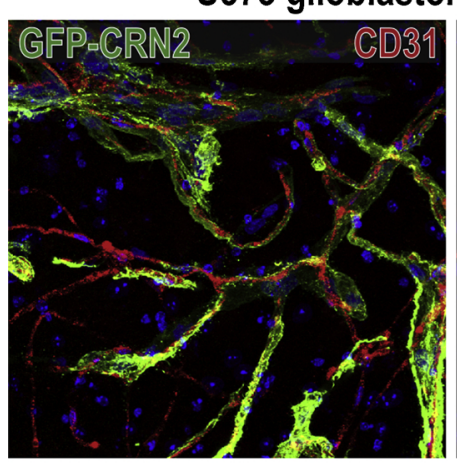

\section{U373 glioblastoma cell invasion}

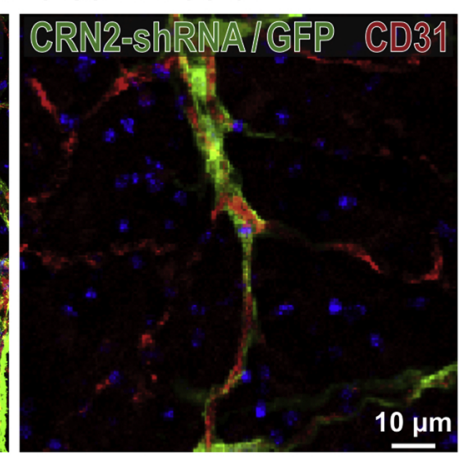

C

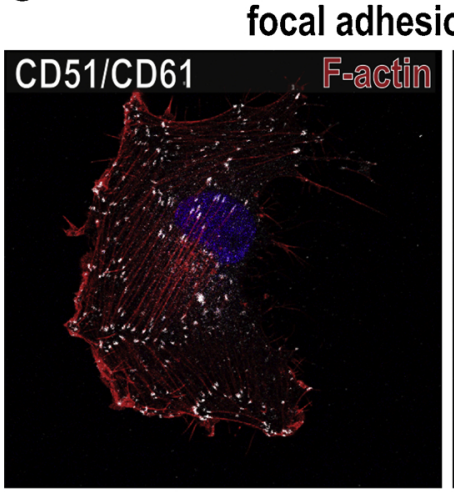

GFP-CRN2

\section{B \\ capillaries encased by \\ U373 glioblastoma cells}

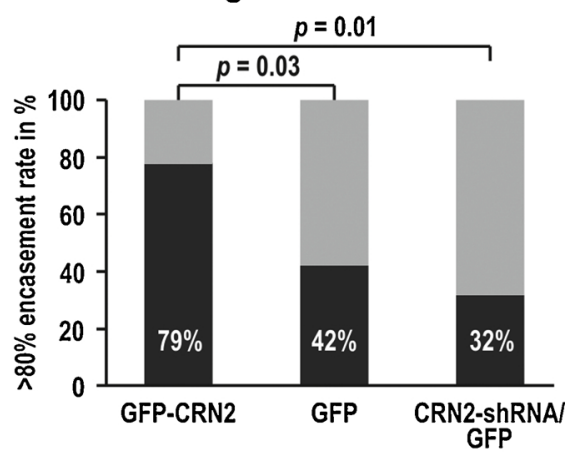

D

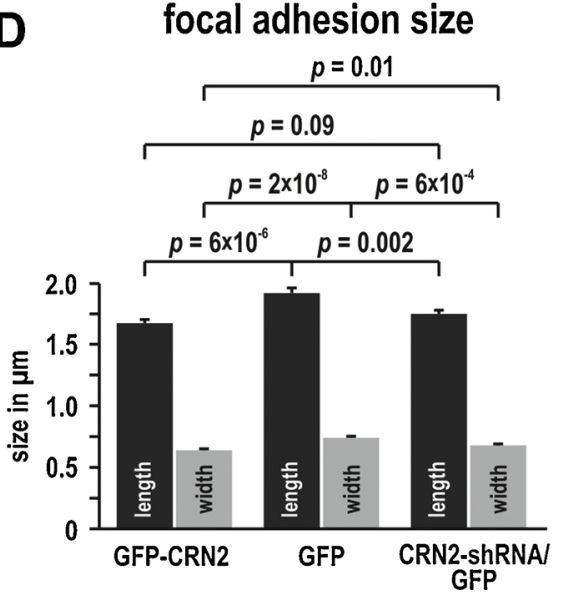

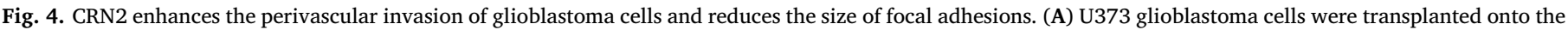

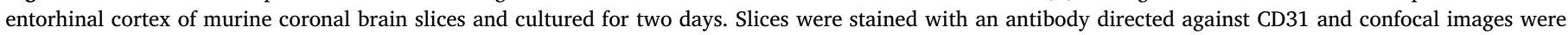

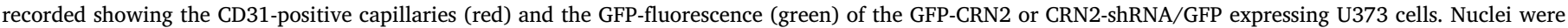

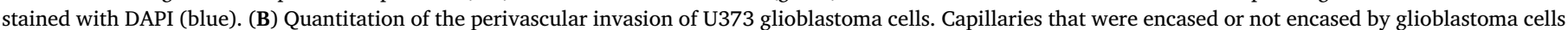

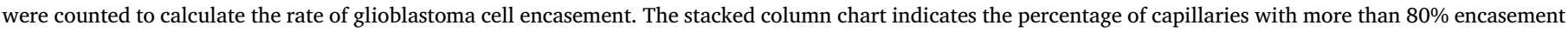

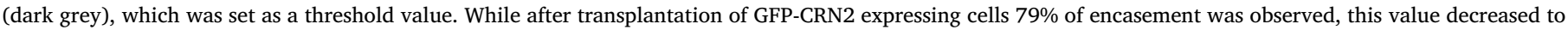

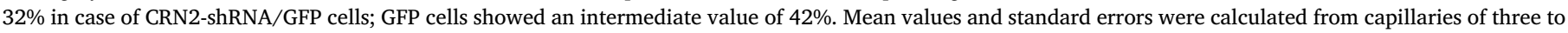

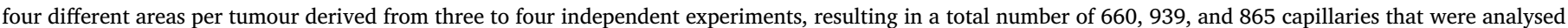

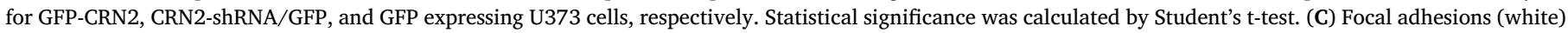

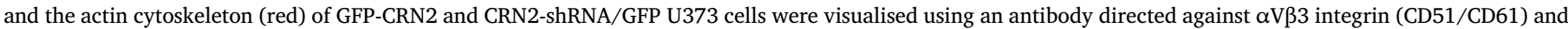

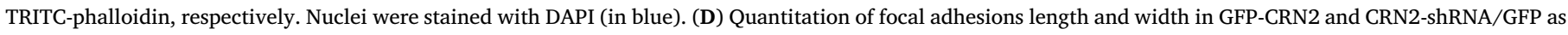

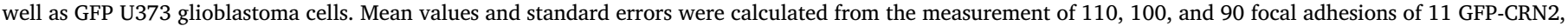
10 CRN2-shRNA/GFP, and 9 GFP cells, respectively, obtained from 3 independent experiments. Statistical significance was calculated by Student's t-test.

higher rate of capillary encasement (79\%) as compared to the CRN2shRNA/GFP cells (32\%; a level of $80 \%$ encasement was set as a threshold value) (Fig. 4B). GFP cells exhibited an intermediate value (42\%). Thus, the presence of CRN2 promotes the perivascular invasion of U373 glioblastoma cells into the brain slice tissue.

As focal adhesions dynamically link the actin cytoskeleton to the extracellular matrix and dysregulation of this cell migration processes is associated with tumour cell invasion (Carragher and Frame, 2004), we examined focal adhesions and the actin cytoskeleton of GFP-CRN2 and CRN2-shRNA/GFP expressing as well as GFP control U373 cells by immunostaining of $\alpha \mathrm{V} \beta 3$ integrin (CD51/CD61, in white) and TRITCphalloidin (in red), respectively (Fig. 4C). Measurement of the dimensions of focal adhesions revealed small but significant reductions in their length and width upon any deviation of the endogenous level of CRN2 (Fig. 4D). Furthermore, GFP-CRN2 expressing cells showed a slightly but statistically significantly reduced focal adhesion width as compared to CRN2-shRNA/GFP cells.

\subsection{CRN2-dependent expression of TIMP4 in glioblastoma tissue}

To shed more light on the molecular role of CRN2 in tumour progression, we searched for novel, cancer-related CRN2 binding partners and signalling pathways. For this purpose, we used the RT ${ }^{2}$ Profiler PCR array "Tumour Metastasis" (Qiagen) to screen for differentially regulated genes using cDNA derived from tumour tissue specimens as well as unaffected brain areas from our glioblastoma mice with and without expression of CRN2. Here, we specifically focused on the comparison of results obtained from glioblastoma specimens with and without expression of CRN2. Out of the 89 genes included in this assay, a statistically significant, CRN2-dependent regulation in glioblastoma of more than two-fold was detected for 12 genes. We found that Etv4, Fn1, Kras, and Lpar6 were down-regulated, whereas Ccl7, Hpse, Igf1, Itga7, Nme1, TIMP4, B2m, and Gusb were up-regulated in the tumour specimens lacking CRN2. Here, we focused on the gene encoding the tissue inhibitor of metalloproteinases 4 (TIMP4), which was 2.14-fold upregulated $(p=0.005)$. The rationale for this selection is based on the 

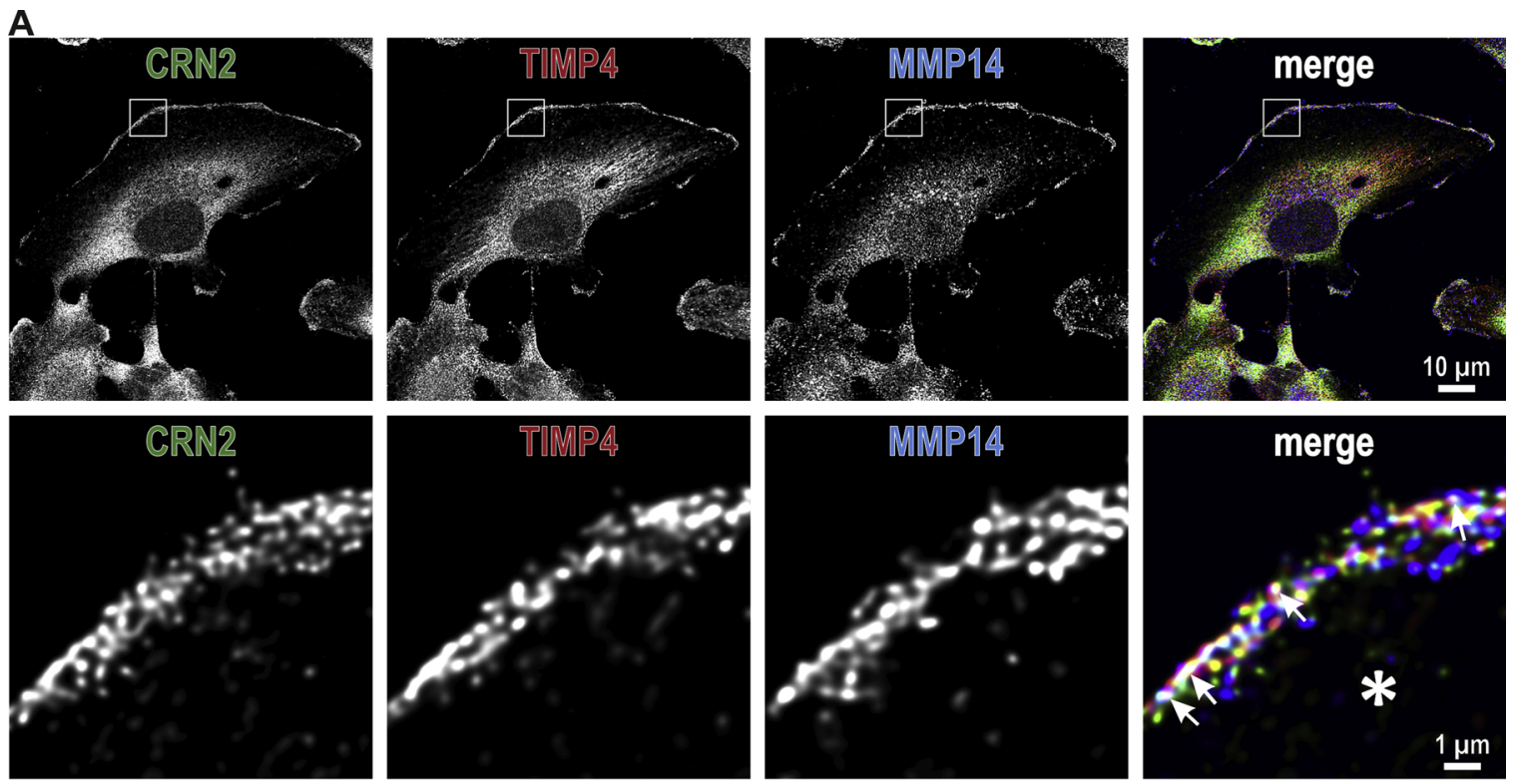

B
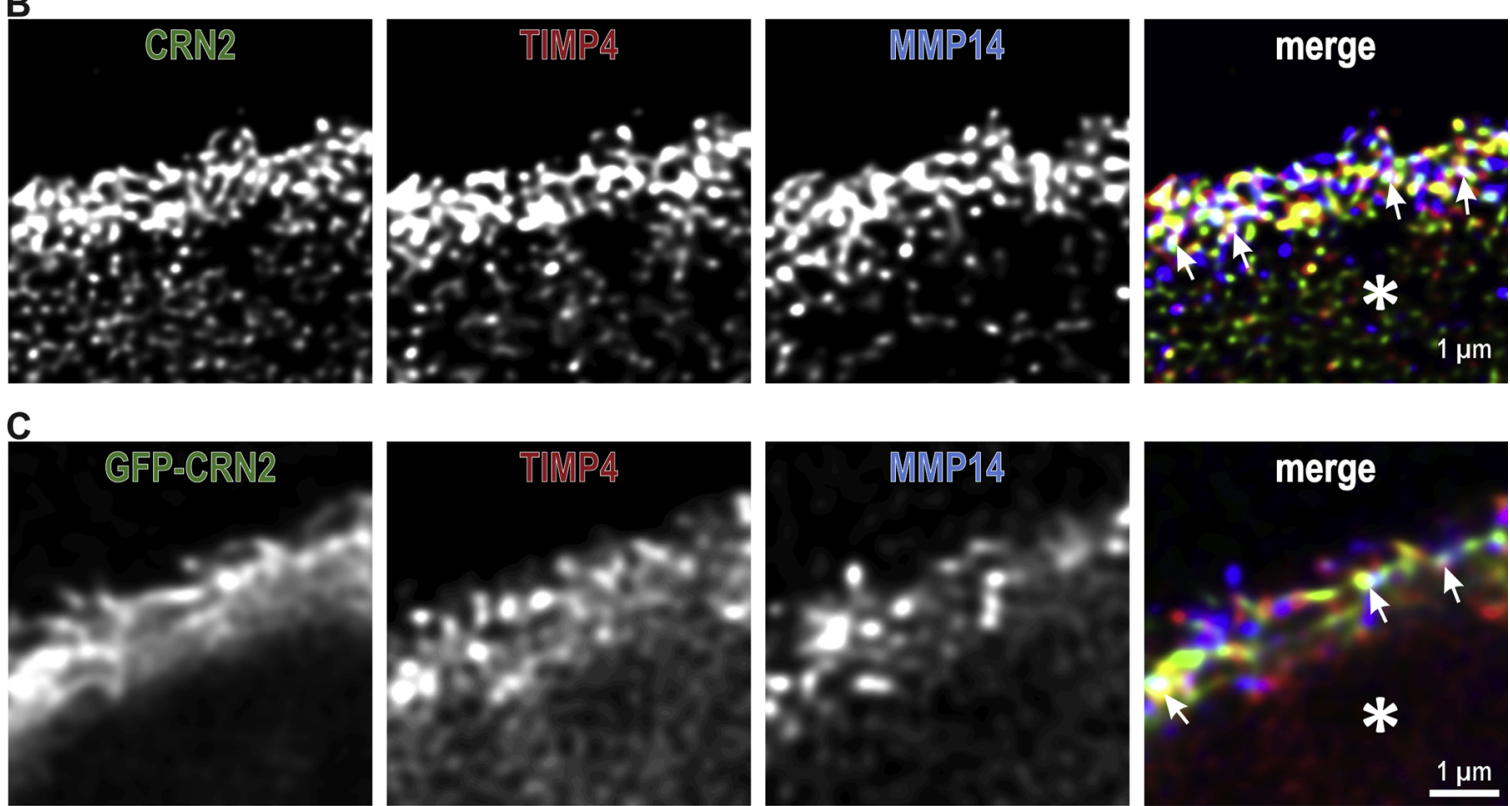

Fig. 5. Distribution of CRN2, TIMP4 and MMP14 in U373 glioblastoma cells revealed partial co-localisation of all three proteins. (A) U373 glioblastoma cells were stained with antibodies directed against CRN2 (green), TIMP4 (red) and MMP14 (blue); overview and higher magnification of the boxed area. Arrows highlight colocalisation of all three proteins at the front of lamellipodia (white). (B) The leading edge of another U373 glioblastoma cell is shown. (C) GFP-CRN2 (green) overexpressing U373 glioblastoma cells were stained with antibodies directed against TIMP4 (red) and MMP14 (blue). (A-C) Asterisks indicate the cytoplasmic side of the higher magnified lamellipodial region. All images were deconvolved using Huygens Essential (Scientific Volume Imaging).

previous observation that TIMP4 is expressed in human brain tumours and interacts with MMP14 (matrix metalloproteinase-14) (Groft et al., 2001). Moreover, TIMP4 has been reported as an effective inhibitor of the MMP14 catalytic activity (Bigg et al., 2001). Thus, we included all three proteins, CRN2, TIMP4, and MMP14, in our further analyses.

\subsection{Partial co-localisation of CRN2, TIMP4 and MMP14 at the front of lamellipodia}

As a next step, we addressed the subcellular localisations of CRN2, TIMP4, and MMP14 by immunofluorescence analysis of U373 glioblastoma cells. In addition to cytoplasmic pools, all three proteins showed marked enrichments at the plasma membrane, in particular at the front of lamellipodia (Fig. 5A). Single confocal planes recorded at higher magnification in conjunction with image deconvolution revealed co-localisations of CRN2 and TIMP4 (in yellow), CRN2 and MMP14 (in cyan), TIMP4 and MMP14 (in magenta), and, notably, of all three proteins (in white) predominantly at the leading edge of lamellipodia (highlighted by white arrows) (Fig. 5A lower row, 5B). A similar pattern of co-localisations, though with a more diffuse distribution of CRN2, was detected in U373 cells stably overexpressing GFP-CRN2 (Fig. 5C).

\subsection{CRN2, TIMP4 and MMP14 mutually interact and form a ternary protein complex}

Based on this immunofluorescence data, we performed luminescence-based mammalian interactome mapping (LUMIER) assays to detect putative protein interactions. CRN2, TIMP4, and MMP14 were expressed as Renilla luciferase, Firefly luciferase, and Protein A fusion proteins, and Renilla luciferase (left) and Firefly luciferase (right) 
luminescence values were recorded (Fig. 6A). This protein interaction assay showed TIMP4 and MMP14 as novel binding partners of CRN2. Moreover, the already described interaction between TIMP4 and
MMP14 could be verified. Notably, we detected a complex formation of all three proteins by the simultaneous measurement of the Renilla and Firefly luciferase luminescence signal intensities. The formation of

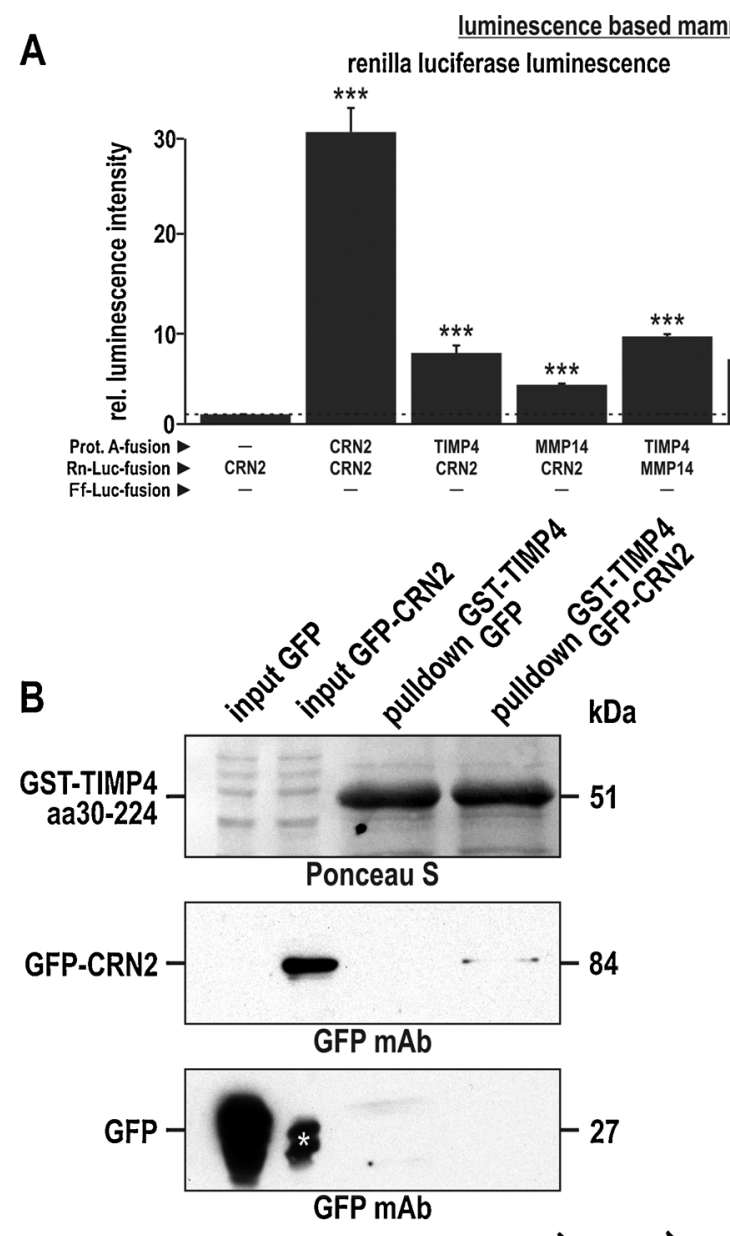

luminescence based mammalian interactome mapping
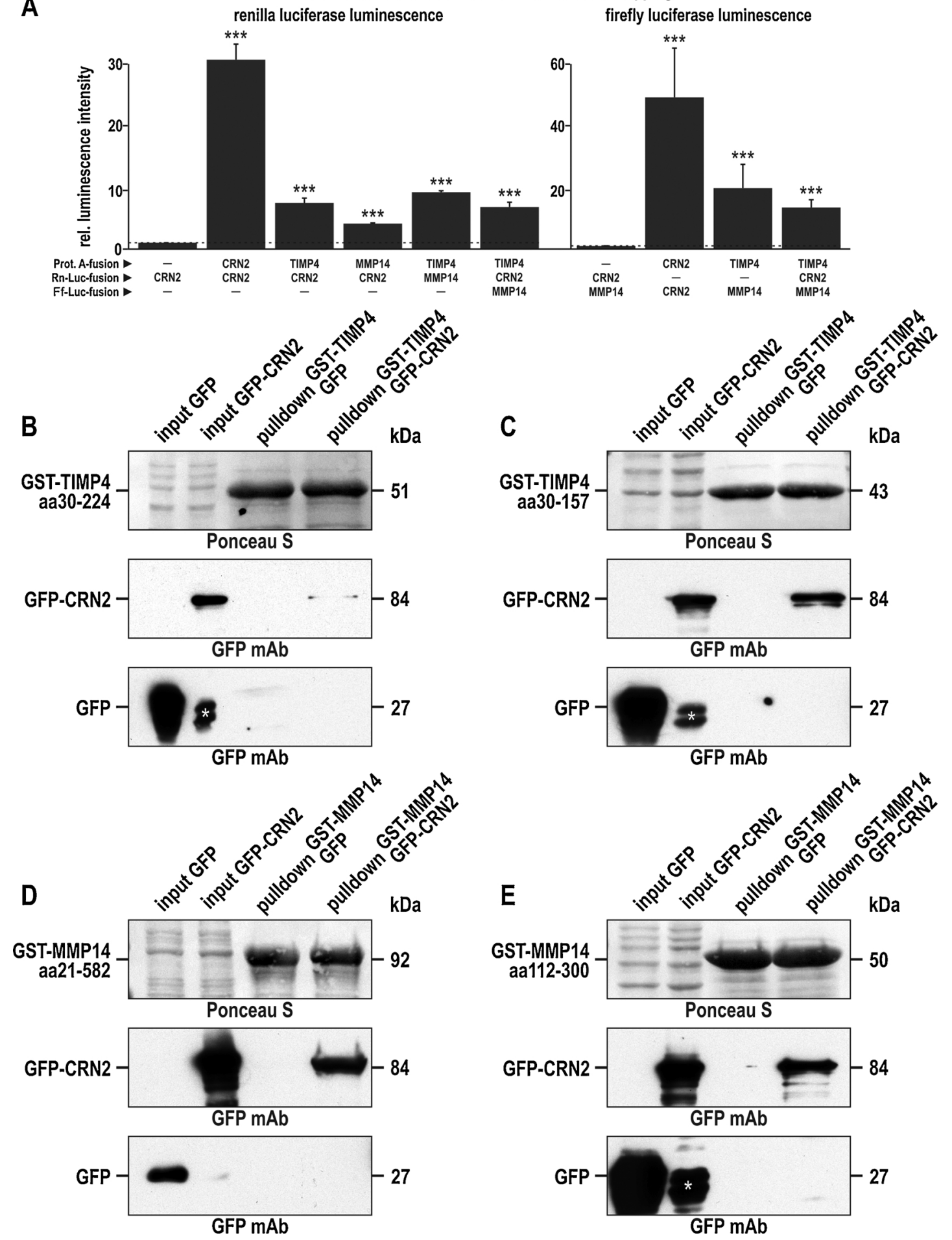

$\mathbf{F}$

\begin{tabular}{|c|c|c|c|c|c|c|c|c|c|c|}
\cline { 2 - 9 } & \multicolumn{3}{|c|}{ TIMP4 } & \multicolumn{9}{c|}{ MMP14 } \\
\cline { 2 - 10 } & $\begin{array}{c}\text { full-length } \\
\text { aa30-224 }\end{array}$ & $\begin{array}{c}\text { N-TIMP4 } \\
\text { aa30-157 }\end{array}$ & $\begin{array}{c}\text { C-TIMP } \\
\text { aa158-224 }\end{array}$ & $\begin{array}{c}\text { full-length } \\
\text { aa21-582 }\end{array}$ & $\begin{array}{c}\text { extra-cell } \\
\text { aa21-541 }\end{array}$ & $\begin{array}{c}\text { propeptide } \\
\text { aa21-111 }\end{array}$ & $\begin{array}{c}\text { peptidase } \\
\text { aa112-300 }\end{array}$ & $\begin{array}{c}\text { propeptidel } \\
\text { peptidase } \\
\text { aa21-300 }\end{array}$ & $\begin{array}{c}\text { hemopoxin } \\
\text { aa301-541 }\end{array}$ & $\begin{array}{c}\text { intra-cell } \\
\text { aa563-582 }\end{array}$ \\
\hline $\begin{array}{l}\text { interaction } \\
\text { with CRN2 }\end{array}$ & $(\sqrt{ })$ & $\sqrt{ }$ & $\boldsymbol{X}$ & $\sqrt{ }$ & $\sqrt{ }$ & $\mathbf{X}$ & $\sqrt{ }$ & $(\sqrt{ }$ & $\mathbf{X}$ & $\boldsymbol{X}$ \\
\hline
\end{tabular}




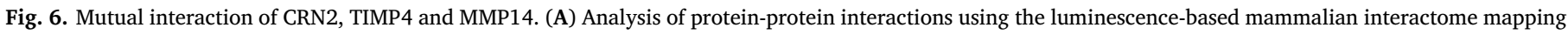

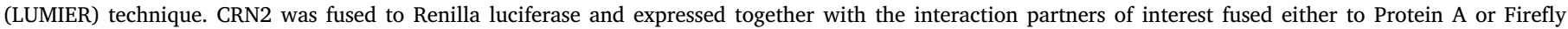

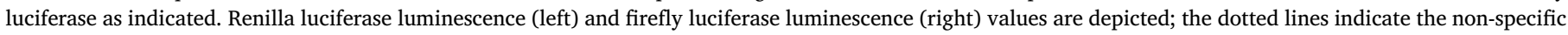

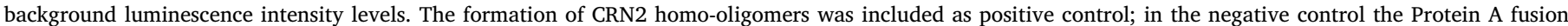

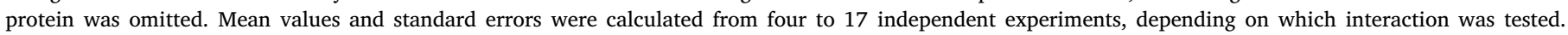

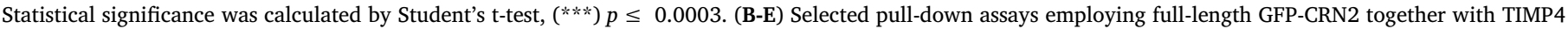

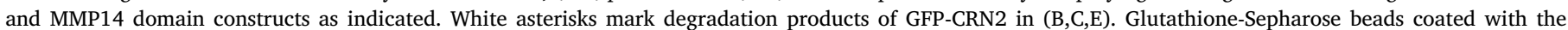

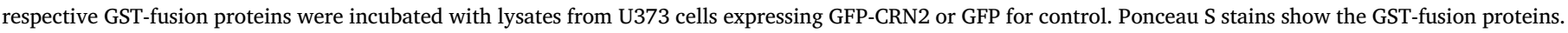

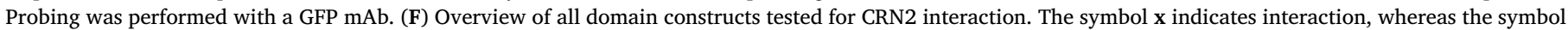
$\checkmark$ indicates no interaction with GFP-CRN2. The symbol $(\checkmark)$ indicates weak binding. Assays were performed as described for (B)-(E).

CRN2 oligomers was included as a positive control, and as a negative control the Protein A fusion protein was omitted (Fig. 6A).

\subsection{Mapping of the CRN2 - TIMP4 and CRN2 - MMP14 interaction domains}

We used bacterially expressed and purified TIMP4 GST-fusion constructs to precipitate full-length GFP-CRN2 from lysates of stably expressing U373 glioblastoma cells. The following TIMP4 variants were used (Fig. 6F): (1) mature full-length form lacking the very N-terminal signal peptide, amino acids 30-224; (2) N-terminal domain, amino acids 30-157 and (3) C-terminal domain, amino acids 158-224. Glutathione-Sepharose beads coated with a GST-fusion protein were incubated with lysates from U373 glioblastoma cells either expressing GFP-tagged CRN2 or GFP alone, used for the pull-down, and analysed by GFP immunoblotting. Here, the $\mathrm{N}$ domain of TIMP4 could precipitate GFP-CRN2 from cell lysates but not GFP alone, which was used for control (Fig. 6C,F). Full-length TIMP4 also interacted with CRN2, however, much weaker (Fig. 6B,F). The C domain of TIMP4 showed no binding at all (Fig. 6F).

We performed analogous experiments for CRN2 and MMP14 and used the following domains of MMP14 fused to GST (Fig. 6F): (1) mature full-length protein without the N-terminal signal peptide, amino acids 21-582; (2) complete extra-cellular part, amino acids 21-541; (3) propeptide domain, amino acids 21-111; (4) peptidase activity domain, amino acids 112-300; (5) propeptide plus peptidase activity domain, amino acids 21-300; (6) hemopexin domain, amino acids 301-541; and (7) the small intra-cellular part, amino acids 563-582. In these pulldown assays, the mature full-length MMP14 protein (Fig. 6D,F), the extra-cellular part (Fig. 6F), the peptidase activity domain (Fig. 6E,F), and the propeptide including the peptidase activity domain (Fig. 6F) were able to pull-down GFP-CRN2. In contrast, for the propeptide domain alone, the hemopexin domain, and the intra-cellular part of MMP14 no binding of GFP-CRN2 could be detected (Fig. 6F). Thus, these data suggest that the peptidase activity domain of MMP14 is the minimal binding region for the interaction with CRN2.

\subsection{CRN2-dependent secretion of TIMP4 and activity regulation of MMP14}

To address putative functional effects of CRN2 on TIMP4 and MMP14, we measured the secretion of TIMP4 by U373 glioblastoma cells and the catalytic activity of recombinant MMP14. Growth medium supernatants from GFP-CRN2 and CRN2-shRNA/GFP U373 glioblastoma cells were collected after 24 to $72 \mathrm{~h}$ and used for ELISA measurements using 96-well plates coated with an antibody specific for human TIMP4. This analysis revealed that GFP-CRN2 U373 cells on average secreted $612 \mathrm{pg} / \mathrm{ml}$ TIMP4 as compared to $501 \mathrm{pg} / \mathrm{ml}$ in case of CRN2-shRNA/GFP U373 cells (Fig. 7A).

For MMP14 catalytic activity measurements, we used a quenched fluorogenic peptide in conjunction with the above peptidase activity domain (construct 4). For control, we added NNGH (N-isobutyl-N-(4methoxyphenylsulfonyl)glycyl hydroxamic acid), a potent inhibitor of matrix metalloproteases, and also performed measurements using the enzymatically inactive small intra-cellular MMP14 peptide (construct 7). The reaction mixtures further contained either GFP-CRN2 or GFP for control immunoprecipitated from the stably expressing U373 glioblastoma cells. The MMP14 enzyme activity measurements revealed that the presence of CRN2 significantly enhanced the catalytic activity of the peptidase domain (Fig. 7B). Reactions containing the intra-cellular MMP14 peptide or with the addition of NNGH showed background fluorescence intensity levels. Thus, binding of CRN2 to MMP14 increased the MMP14 catalytic activity.

\subsection{CRN2, TIMP4, and MMP14 - protein interaction in a shared compartment}

The detection of a ternary complex composed of CRN2, TIMP4 and MMP14, their co-localisation at lamellipodia, and the CRN2-dependent regulation of MMP14 catalytic activity raise the question of a shared intracellular compartment of the three proteins or, alternatively, the secretion of CRN2. Firstly, the subcellular localisation of CRN2 in relation to TIMP4 and MMP14 was analysed using sucrose density gradient fractionation (Fig. 7C). CRN2 distributed between fractions 5 and 24 with peaks in fractions 6-8 (0.15-0.3 M sucrose), 17 (1 M sucrose), and $22-23$ of high sucrose density $(2.49 \mathrm{M})$. Fractions of low sucrose density most likely represent CRN2 bound to the membrane-associated actin cytoskeleton, whereas in fractions of higher density CRN2 is associated with membranes that were reported to co-fractionate with ERmarkers (Spoerl et al., 2002). TIMP4 was only present in the low-density fractions 4-7 containing approximately $0.15 \mathrm{M}$ sucrose, while MMP14 could be detected starting from fraction 11 until the highdensity fractions of the sucrose gradient. Fractions 6 as well as 17 and 21 containing the peak intensities of CRN2/TIMP4 and CRN2/MMP14, respectively, were subjected to SDS-PAGE in conjunction with mass spectrometry. While the lower density fraction mainly contained cytosolic and cytoskeleton-related proteins, both higher density fractions additionally contained membrane receptors and proteins regulating lamellipodium assembly and vesicle trafficking. Notably, the latter fractions contained the Ras GTPase-activating-like protein IQGAP1 which regulates the dynamics and assembly of the actin cytoskeleton and also the exocytosis of MMP14 (Sakurai-Yageta et al., 2008).

Secondly, we tested the possibility that CRN2 is released from the cell via exosomes, which have been implicated in cell migration, signalling, and cancer (Bobrie et al., 2012). We purified exosomes from conditioned growth medium of U373 glioblastoma cells stably expressing GFP-CRN2 for immunoblot analysis, and the purified particles were positive for the exosome marker Hsp70. Notably, the exosomes were also positive for both endogenous and GFP-tagged CRN2. Furthermore, they contained MMP14, but we could not detect TIMP4 (Fig. 7D). This data provides first evidence that CRN2 may be transported to the extracellular space via exosomes, where it could become available for its interactions with TIMP4 and MMP14.

\section{Discussion}

The goal of the present study was to further explore the functional role of the actin filament-binding protein CRN2 in the context of glioblastoma multiforme. For this purpose, we crossbred our CRN2 knockout mice with an inducible Tp53/Pten knock-out glioblastoma mouse model (Chow et al., 2011; Maire and Ligon, 2011). Our prior 
comprehensive analysis of the CRN2 knock-out mouse line revealed mild neurological and behavioural alterations. A reduced hearing sensitivity had been described for other WD40-repeat domain proteins
(Bassi et al., 1999), and low abundance of CRN2 has been described in the ventricular hair bundles of chicken inner ear (Shin et al., 2013a). A tumour phenotype could not be detected in this mouse line. Comparing

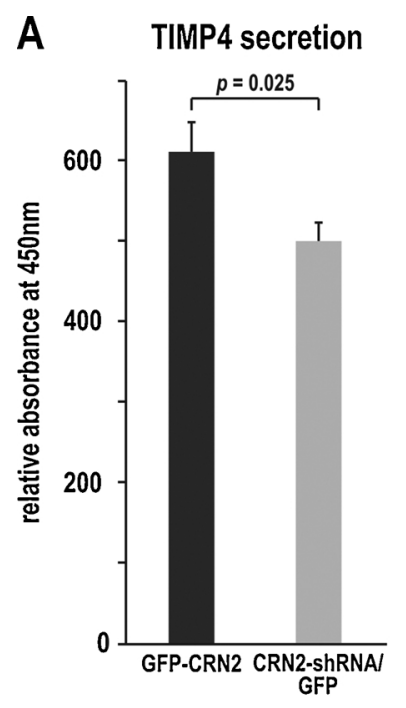

B

MMP14 activity

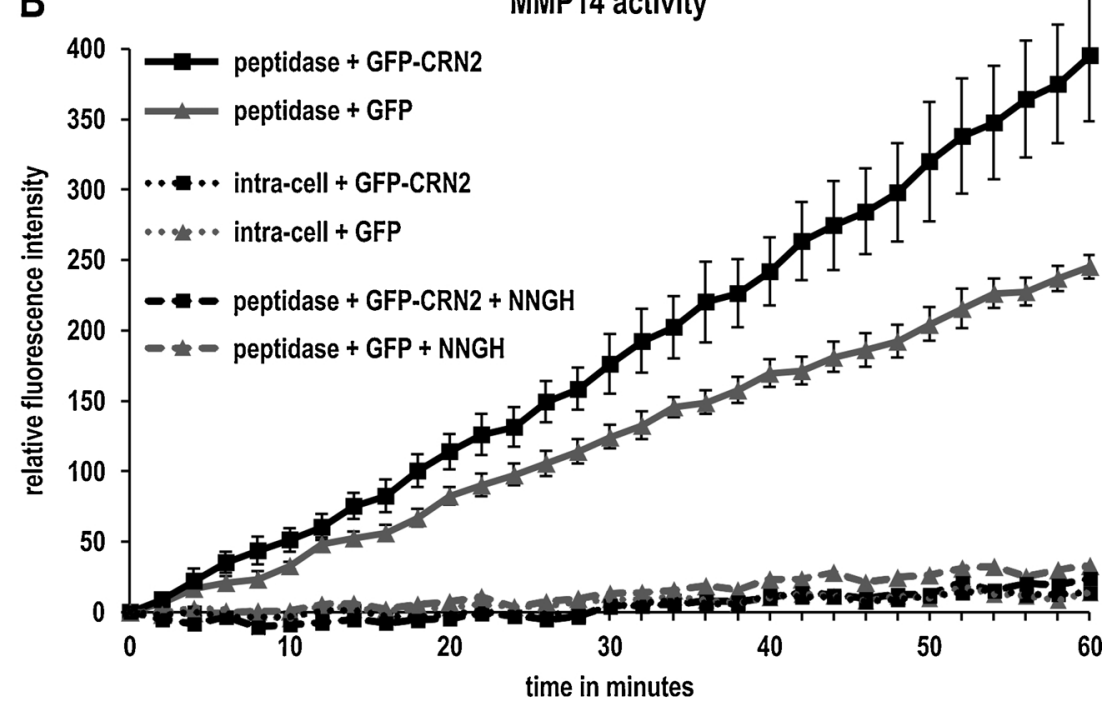

C
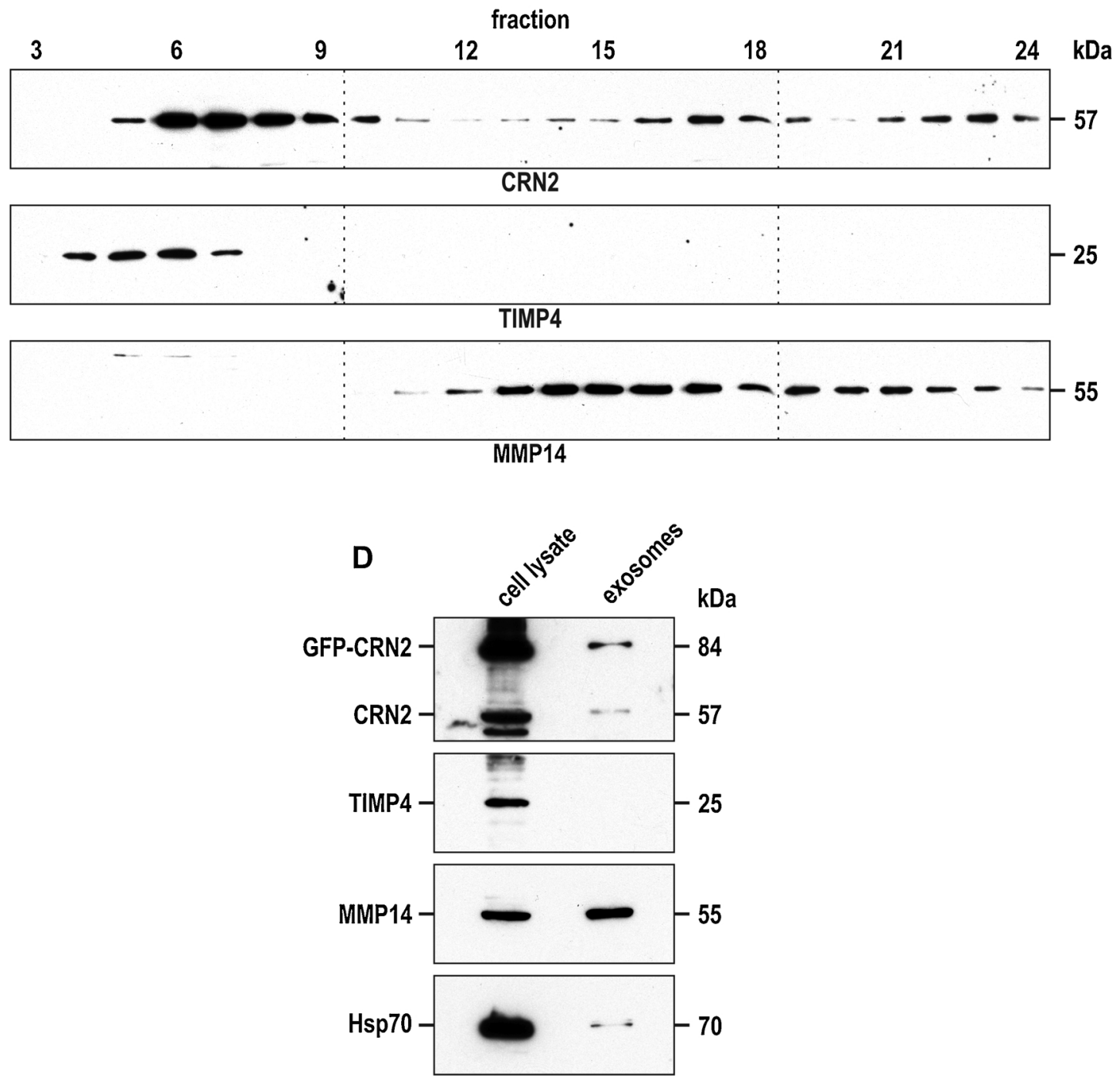

(caption on next page) 


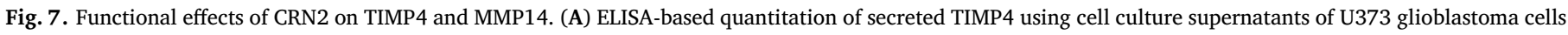

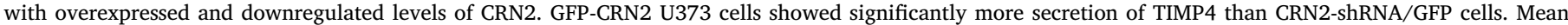

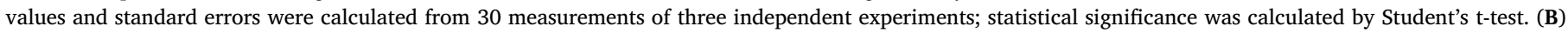

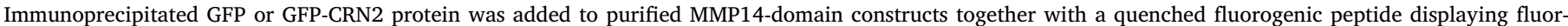

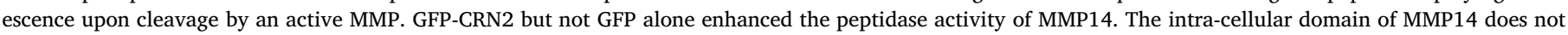

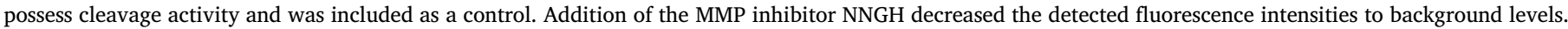

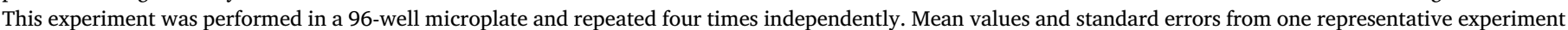

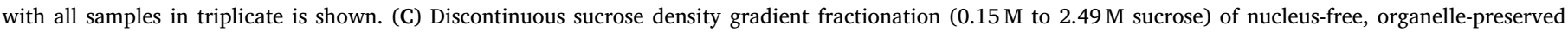

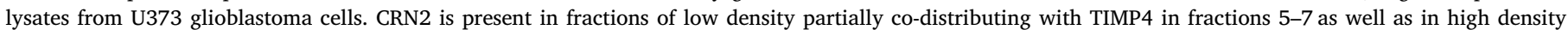

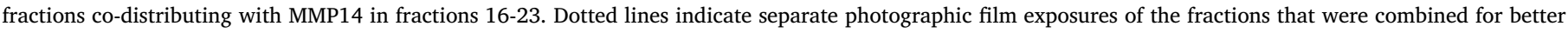

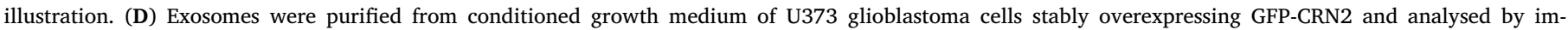
munoblotting using antibodies directed against CRN2, TIMP4, MMP14, and the exosome marker Hsp70.

the Tp53/Pten knock-out (glioblastoma) and Tp53/Pten/CRN2 knockout (glioblastoma with additional CRN2 knock-out) mice, we could not detect a clear difference in the survival rates, which might at least in part be explained by the overall fast growth of this tumour entity.

In a next step, we assessed the role of CRN2 in glioblastoma formation by transplanting U373 glioblastoma cells onto the entorhinal cortex of murine coronal brain slices. Tumour cell infiltration into the surrounding brain tissue was visualized by the extent of capillary encasement, as it had been reported that glioblastoma cells spread from the solid tumour by migrating along blood vessels (Yu et al., 2011). Consistent with our previous findings (Ziemann et al., 2013) we observed a higher encasement of capillaries by glioblastoma cells overexpressing GFP-CRN2 than by CRN2-shRNA/GFP knock-down cells. Since a dysregulated focal adhesion network has been shown to be associated with tumour cell invasion (Carragher and Frame, 2004), we also analysed adhesion sites by visualising the $\alpha \mathrm{V} \beta 3$ integrin (CD51/ CD61) complex and found focal adhesions with the smallest dimensions in our GFP-CRN2 expressing cells. Albeit the observed differences seem to be rather small, GFP-CRN2 glioblastoma cells also have been reported to exhibit a reduced level of cell adhesion as compared to CRN2shRNA/GFP cells (Ziemann et al., 2013), and a CRN2 knock-down in intestinal epithelial cells led to an elevated adhesion (Samarin et al., 2010), which supports our results.

In a second line of experiments, we searched for cancer-related CRN2 interacting proteins and identified TIMP4 as well as MMP14 as novel CRN2 binding partners. CRN2 predominantly interacted with the $\mathrm{N}$ domain of TIMP4, the region of TIMPs which commonly is involved in matrix metalloproteinase inhibition (Lee et al., 2002), and with the peptidase activity domain of MMP14. TIMPs are inhibitors of MMPs and regulate extracellular matrix turnover in normal and diseased conditions (Arpino et al., 2015; Lukaszewicz-Zajac et al., 2014). TIMP4 has been shown to be upregulated in early stages of gliomas, breast and prostate cancers, while being downregulated in advanced stages (Groft et al., 2001; Lee et al., 2006; Zhao et al., 2004). It inhibits the MMP14mediated activation of pro-MMP2 (Bigg et al., 2001). MMP14 exerts a key role during cancer dissemination, where its expression correlates with the malignancy of gliomas and several more types of cancer (Castro-Castro et al., 2016; Seiki et al., 2003a, b). Notably, all three proteins, CRN2, TIMP4 and MMP4, were co-localised at the front of lamellipodia in U373 glioblastoma cells. The localisations of CRN2 at lamellipodia, invadopodia, and cytosolic vesicular structures (Rosentreter et al., 2007; Ziemann et al., 2013) and of MMP14 at invadopodia (Artym et al., 2006; Steffen et al., 2008) have been reported earlier. A more recent study showed that CRN2 is required for invadopodia formation and matrix degradation by breast cancer cells via accumulation at proteolytically active invadopodia formed in close association with collagen fibrils (Castagnino et al., 2018). This study further demonstrated an actin filament-dependent presence of CRN2 on the cytosolic side of MMP14-containing late endosomes/lysosomes that are involved in MMP14 recycling and delivery to invadopodia for surface exposure (Castagnino et al., 2018; Steffen et al., 2008; Williams and Coppolino, 2011). Another way of MMP14 secretion that has been described is the route via exosomes (Hakulinen et al., 2008; Hoshino et al., 2013). Our data adds more complexity to this picture, as we also detected CRN2 in exosomes, and determined a higher secretion of TIMP4 as well as an increased MMP14 catalytic activity in presence of CRN2.

In the context of glioblastoma, our biochemical and subcellular localisation data points into the direction that CRN2 may act as a proinvasive effector within the tumour cell microenvironment, and we hypothesise that the cell surface might be the shared compartment in which CRN2, TIMP4, and MMP14 could form a functional protein complex. In this respect, the current model of MMP2 activation at the cell surface involves a transient ternary complex of one MMP14 molecule of a MMP14 homo-dimer that interacts with the $\mathrm{N}$ domain of TIMP2, which further binds to proMMP2 via its $\mathrm{C}$ domain. The latter is converted to active MMP2 by the second MMP14 molecule (Fig. 2 within reference (Gifford and Itoh, 2019)). Thus, TIMP2, originally described as MMP14 inhibitor, rather has a role in the activation of MMP14-mediated proMMP2 conversion. Since it has been shown that TIMP4 cannot replace TIMP2 in this functional trimer, it only can inhibit MMP14 and its intermolecular autocatalytic processing, but neither form a MMP14-TIMP4-proMMP2 complex nor promote the conversion of proMMP2 (Bigg et al., 2001; Hernandez-Barrantes et al., 2001).

How could a complex composed of CRN2, TIMP4 and MMP14 operate? We propose a model in which cell surface exposed MMP14 via its peptidase domain would interact with a bridging CRN2 that additionally would interact with the $\mathrm{N}$ domain of TIMP4. In such a MMP14-CRN2-TIMP4 protein complex (Fig. 6A) the cell surface bound MMP14 would not be inhibited by the potent inhibitor TIMP4, as the N domain of TIMP4 would be engaged in the interaction with CRN2. However, CRN2 could activate MMP14 as shown in our assay (Fig. 7B). The active MMP14 could then directly degrade components of the pericellular extracellular matrix and shed adhesion molecules. In this scenario, the primary function of the sequestrated, surface bound TIMP4 would not be the inhibition of MMPs like e.g. MMP2 (Kai et al., 2002; Melendez-Zajgla et al., 2008). Rather, the C domain of TIMP4 could interfere with signalling pathways, as it has previously been shown for TIMP4 to promote tumour growth by inhibiting tumour cell apoptosis via interaction with the tetraspanin CD63 of neighbouring cells (Melendez-Zajgla et al., 2008; Pruefer et al., 2016; Rorive et al., 2010; Stetler-Stevenson, 2008).

\section{Conclusions}

In the present study, we further explored the functional role of the actin filament-binding protein CRN2 in the context of glioblastoma multiforme. We performed a multi-scale analysis of the tumour-promoting effects of CRN2 in vivo, ex vivo, and in vitro. Key findings of our study are, a) the detection of neurological and behavioural alterations in CRN2 knock-out mice, b) a higher tumour cell encasement of murine brain slice capillaries by glioblastoma cells overexpressing CRN2, c) the identification of two novel and tumour-relevant CRN2 interaction partners, namely TIMP4 and MMP14, d) a CRN2-dependent secretion of TIMP4 and activity regulation of MMP14, and e) the presence of CRN2 
in exosomes. In the context of glioblastoma, these newly established CRN2 functions are suggestive of CRN2 as a pro-invasive effector within the tumour cell microenvironment.

\section{Funding}

Grant support by the German Research Foundation (DFG) (grants NO 113/22-2 to AAN and CSC, and CL 381/2-1 to CSC) and the German Federal Ministry of Education and Research (Infrafrontier grant $01 \mathrm{KX} 1012$ to MHdA) is gratefully acknowledged.

\section{Declaration of Competing Interest}

The authors declare that they have no conflicts of interest.

\section{Acknowledgments}

The glioblastoma mouse model was kindly provided by Suzanne J. Baker, St. Jude Children's Research Hospital, Memphis, USA, and was generated using a GFAP-creER allele generated by the Baker lab, combined with a Tp53 allele kindly provided by Anton Berns, Netherlands Cancer Institute, Amsterdam, The Netherlands, and a Pten allele kindly provided by Tak W. Mak, Ontario Cancer Institute, University Health Network, Toronto, Ontario, Canada. We thank Marija Marko for technical assistance and helpful discussion.

\section{Appendix A}

German Mouse Clinic, Helmholtz Zentrum München, German Research Center for Environmental Health GmbH, 85764 Neuherberg, Germany:

Antonio Aguilar-Pimentel ${ }^{1}$, Carsten Schmidt-Weber ${ }^{2}$, Thomas Klopstock $^{3,8,9,10}$, Thure Adler ${ }^{1}$, Irina Treise ${ }^{1}$, Dirk H. Busch ${ }^{4}$, Kristin Moreth $^{1}$, Sabine M. Hölter ${ }^{1,5}$, Annemarie Zimprich ${ }^{1,5}$, Wolfgang Wurst $^{5,8,9,11}$, Oana Amarie ${ }^{1,5}$, Jochen Graw ${ }^{5}$, Jan Rozman ${ }^{1,7}$, Julia Calzada-Wack $^{1}$, Ildiko Racz ${ }^{6}$, Birgit Rathkolb ${ }^{1,6,7}$, Eckhard Wolf ${ }^{6}$, Manuela Östereicher ${ }^{1}$, Gregor Miller ${ }^{1}$, Christoph Lengger ${ }^{1}$, Holger Maier $^{1}$, Claudia Stoeger ${ }^{1}$, Stefanie Leuchtenberger ${ }^{1}$, Valérie GailusDurner $^{1}$, Helmut Fuchs ${ }^{1}$

${ }^{1}$ German Mouse Clinic, Institute of Experimental Genetics, Helmholtz Zentrum München, German Research Center for Environmental Health GmbH, 85764 Neuherberg, Germany

${ }^{2}$ Center of Allergy \& Environment (ZAUM), Technische Universität München, and Helmholtz Zentrum München, 85764 Neuherberg, Germany

${ }^{3}$ Department of Neurology, Friedrich-Baur-Institut, LudwigMaximilians-Universität München, 80336 Munich, Germany

${ }^{4}$ Institute for Medical Microbiology, Immunology and Hygiene,

Technical University of Munich, 81675 Munich, Germany

${ }^{5}$ Institute of Developmental Genetics, Helmholtz Zentrum München, German Research Center for Environmental Health GmbH, 85764 Neuherberg, Germany

${ }^{6}$ Ludwig-Maximilians-Universität München, Gene Center, Institute of Molecular Animal Breeding and Biotechnology, 81377 Munich, Germany

${ }^{7}$ Member of German Center for Diabetes Research (DZD), 85764 Neuherberg, Germany

${ }^{8}$ Deutsches Institut für Neurodegenerative Erkrankungen (DZNE) Site Munich, 80336 Munich, Germany

${ }^{9}$ Munich Cluster for Systems Neurology (SyNergy), AdolfButenandt-Institut, Ludwig-Maximilians-Universität München, 80336 Munich, Germany

${ }^{10}$ German Network for Mitochondrial Disorders (mitoNET)

${ }^{11}$ Chair of Developmental Genetics, Center of Life and Food Sciences Weihenstephan, Technische Universität München, 85764 Neuherberg, Germany

\section{References}

Appleton, B.A., Wu, P., Wiesmann, C., 2006. The crystal structure of murine coronin-1: a regulator of actin cytoskeletal dynamics in lymphocytes. Structure 14, 87-96.

Arpino, V., Brock, M., Gill, S.E., 2015. The role of TIMPs in regulation of extracellular matrix proteolysis. Matrix Biol. 44-46, 247-254.

Artym, V.V., Zhang, Y., Seillier-Moiseiwitsch, F., Yamada, K.M., Mueller, S.C., 2006. Dynamic interactions of cortactin and membrane type 1 matrix metalloproteinase at invadopodia: defining the stages of invadopodia formation and function. Cancer Res. 66, 3034-3043.

Bassi, M.T., Ramesar, R.S., Caciotti, B., Winship, I.M., De Grandi, A., Riboni, M., Townes, P.L., Beighton, P., Ballabio, A., Borsani, G., 1999. X-linked late-onset sensorineural deafness caused by a deletion involving OA1 and a novel gene containing WD-40 repeats. Am. J. Hum. Genet. 64, 1604-1616.

Behrens, J., Solga, R., Ziemann, A., Rastetter, R.H., Berwanger, C., Herrmann, H., Noegel, A.A., Clemen, C.S., 2016. Coronin 1C-free primary mouse fibroblasts exhibit robust rearrangements in the orientation of actin filaments, microtubules and intermediate filaments. Eur. J. Cell Biol. 95, 239-251.

Bigg, H.F., Morrison, C.J., Butler, G.S., Bogoyevitch, M.A., Wang, Z., Soloway, P.D., Overall, C.M., 2001. Tissue inhibitor of metalloproteinases-4 inhibits but does not support the activation of gelatinase A via efficient inhibition of membrane type 1 matrix metalloproteinase. Cancer Res. 61, 3610-3618.

Blümcke, I., Becker, A.J., Normann, S., Hans, V., Riederer, B.M., Krajewski, S., Wiestler, O.D., Reifenberger, G., 2001. Distinct expression pattern of microtubule-associated protein-2 in human oligodendrogliomas and glial precursor cells. J. Neuropathol. Exp. Neurol. 60, 984-993.

Bobrie, A., Krumeich, S., Reyal, F., Recchi, C., Moita, L.F., Seabra, M.C., Ostrowski, M., Thery, C., 2012. Rab27a supports exosome-dependent and -independent mechanisms that modify the tumor microenvironment and can promote tumor progression. Cancer Res. 72, 4920-4930.

Carragher, N.O., Frame, M.C., 2004. Focal adhesion and actin dynamics: a place where kinases and proteases meet to promote invasion. Trends Cell Biol. 14, 241-249.

Castagnino, A., Castro-Castro, A., Irondelle, M., Guichard, A., Lodillinsky, C., Fuhrmann, L., Vacher, S., Aguera-Gonzalez, S., Zagryazhskaya-Masson, A., Romao, M., El Kesrouani, C., Noegel, A.A., Dubois, T., Raposo, G., Bear, J.E., Clemen, C.S., VincentSalomon, A., Bieche, I., Chavrier, P., 2018. Coronin 1C promotes triple-negative breast cancer invasiveness through regulation of MT1-MMP traffic and invadopodia function. Oncogene.

Castro-Castro, A., Marchesin, V., Monteiro, P., Lodillinsky, C., Rossé, C., Chavrier, P., 2016. Cellular and molecular mechanisms of MT1-MMP-dependent cancer cell invasion. Annu. Rev. Cell Dev. Biol. 32, 555-576.

Chan, K.T., Roadcap, D.W., Holoweckyj, N., Bear, J.E., 2012. Coronin 1C harbours a second actin-binding site that confers co-operative binding to F-actin. Biochem. J. 444, 89-96.

Cheng, X., Wang, X., Wu, Z., Tan, S., Zhu, T., Ding, K., 2019. CORO1C expression is associated with poor survival rates in gastric cancer and promotes metastasis in vitro. FEBS Open Bio 9, 1097-1108.

Chow, L.M., Endersby, R., Zhu, X., Rankin, S., Qu, C., Zhang, J., Broniscer, A., Ellison, D.W., Baker, S.J., 2011. Cooperativity within and among Pten, p53, and Rb pathways induces high-grade astrocytoma in adult brain. Cancer Cell 19, 305-316.

Chow, L.M., Zhang, J., Baker, S.J., 2008. Inducible Cre recombinase activity in mouse mature astrocytes and adult neural precursor cells. Transgenic Res. 17, 919-928.

Clemen, C.S., Eichinger, L., Rybakin, V., 2008. The Coronin Family of Proteins. Landes Bioscience. Austin \& Springer, Berlin.

Clemen, C.S., Marko, M., Strucksberg, K.H., Behrens, J., Wittig, I., Gärtner, L., Winter, L. Chevessier, F., Matthias, J., Türk, M., Tangavelou, K., Schütz, J., Arhzaouy, K., Klopffleisch, K., Hanisch, F.G., Rottbauer, W., Blümcke, I., Just, S., Eichinger, L., Hofmann, A., Schröder, R., 2015. VCP and PSMF1: antagonistic regulators of proteasome activity. Biochem. Biophys. Res. Commun. 463, 1210-1217.

de Hostos, E.L., Bradtke, B., Lottspeich, F., Guggenheim, R., Gerisch, G., 1991. Coronin, an actin binding protein of Dictyostelium discoideum localized to cell surface projections, has sequence similarities to G protein beta subunits. EMBO J. 10, 4097-4104.

Eckert, C., Hammesfahr, B., Kollmar, M., 2011. A holistic phylogeny of the coronin gene family reveals an ancient origin of the tandem-coronin, defines a new subfamily, and predicts protein function. BMC Evol. Biol. 11, 268.

Fuchs, H., Aguilar-Pimentel, J.A., Amarie, O.V., Becker, L., Calzada-Wack, J., Cho, Y.L., Garrett, L., Holter, S.M., Irmler, M., Kistler, M., Kraiger, M., Mayer-Kuckuk, P., Moreth, K., Rathkolb, B., Rozman, J., da Silva Buttkus, P., Treise, I., Zimprich, A., Gampe, K., Hutterer, C., Stoger, C., Leuchtenberger, S., Maier, H., Miller, M., Scheideler, A., Wu, M., Beckers, J., Bekeredjian, R., Brielmeier, M., Busch, D.H., Klingenspor, M., Klopstock, T., Ollert, M., Schmidt-Weber, C., Stoger, T., Wolf, E., Wurst, W., Yildirim, A.O., Zimmer, A., Gailus-Durner, V., Hrabe de Angelis, M., 2018. Understanding gene functions and disease mechanisms: phenotyping pipelines in the German Mouse Clinic. Behav. Brain Res. 352, 187-196.

Fuchs, H., Gailus-Durner, V., Adler, T., Aguilar-Pimentel, J.A., Becker, L., Calzada-Wack, J., Da Silva-Buttkus, P., Neff, F., Gotz, A., Hans, W., Holter, S.M., Horsch, M. Kastenmuller, G., Kemter, E., Lengger, C., Maier, H., Matloka, M., Moller, G., Naton, B., Prehn, C., Puk, O., Racz, I., Rathkolb, B., Romisch-Margl, W., Rozman, J., WangSattler, R., Schrewe, A., Stoger, C., Tost, M., Adamski, J., Aigner, B., Beckers, J., Behrendt, H., Busch, D.H., Esposito, I., Graw, J., Illig, T., Ivandic, B., Klingenspor, M., Klopstock, T., Kremmer, E., Mempel, M., Neschen, S., Ollert, M., Schulz, H., Suhre, K., Wolf, E., Wurst, W., Zimmer, A., Hrabe de Angelis, M., 2011. Mouse phenotyping. Methods 53, 120-135.

Fuchs, H., Gailus-Durner, V., Neschen, S., Adler, T., Afonso, L.C., Aguilar-Pimentel, J.A., 
Becker, L., Bohla, A., Calzada-Wack, J., Cohrs, C., Dewert, A., Fridrich, B., Garrett, L., Glasl, L., Gotz, A., Hans, W., Holter, S.M., Horsch, M., Hurt, A., Janas, E., Janik, D., Kahle, M., Kistler, M., Klein-Rodewald, T., Lengger, C., Ludwig, T., Maier, H., Marschall, S., Micklich, K., Moller, G., Naton, B., Prehn, C., Puk, O., Racz, I., Rass, M., Rathkolb, B., Rozman, J., Scheerer, M., Schiller, E., Schrewe, A., Steinkamp, R., Stoger, C., Sun, M., Szymczak, W., Treise, I., Vargas Panesso, I.L., Vernaleken, A.M., Willershauser, M., Wolff-Muscate, A., Zeh, R., Adamski, J., Beckers, J., Bekeredjian, R., Busch, D.H., Eickelberg, O., Favor, J., Graw, J., Hofler, H., Hoschen, C., Katus, H., Klingenspor, M., Klopstock, T., Neff, F., Ollert, M., Schulz, H., Stoger, T., Wolf, E., Wurst, W., Yildirim, A.O., Zimmer, A., Hrabe de Angelis, M., 2012. Innovations in phenotyping of mouse models in the German Mouse Clinic. Mamm. Genome 23, 611-622.

Gailus-Durner, V., Fuchs, H., Becker, L., Bolle, I., Brielmeier, M., Calzada-Wack, J., Elvert, R., Ehrhardt, N., Dalke, C., Franz, T.J., Grundner-Culemann, E., Hammelbacher, S., Holter, S.M., Holzlwimmer, G., Horsch, M., Javaheri, A., Kalaydjiev, S.V., Klempt, M., Kling, E., Kunder, S., Lengger, C., Lisse, T., Mijalski, T., Naton, B., Pedersen, V., Prehn, C., Przemeck, G., Racz, I., Reinhard, C., Reitmeir, P., Schneider, I., Schrewe, A., Steinkamp, R., Zybill, C., Adamski, J., Beckers, J., Behrendt, H., Favor, J., Graw, J., Heldmaier, G., Hofler, H., Ivandic, B., Katus, H., Kirchhof, P., Klingenspor, M., Klopstock, T., Lengeling, A., Muller, W., Ohl, F., Ollert, M., Quintanilla-Martinez, L., Schmidt, J., Schulz, H., Wolf, E., Wurst, W., Zimmer, A., Busch, D.H., de Angelis, M.H., 2005. Introducing the German Mouse Clinic: open access platform for standardized phenotyping. Nat. Methods 2, 403-404.

Gifford, V., Itoh, Y., 2019. MT1-MMP-dependent cell migration: proteolytic and nonproteolytic mechanisms. Biochem. Soc. Trans. 47, 811-826.

Groft, L.L., Muzik, H., Rewcastle, N.B., Johnston, R.N., Knäuper, V., Lafleur, M.A., Forsyth, P.A., Edwards, D.R., 2001. Differential expression and localization of TIMP-1 and TIMP-4 in human gliomas. Br. J. Cancer 85, 55-63.

Hakulinen, J., Sankkila, L., Sugiyama, N., Lehti, K., Keski-Oja, J., 2008. Secretion of active membrane type 1 matrix metalloproteinase (MMP-14) into extracellular space in microvesicular exosomes. J. Cell. Biochem. 105, 1211-1218.

Hernandez-Barrantes, S., Shimura, Y., Soloway, P.D., Sang, Q.A., Fridman, R., 2001. Differential roles of TIMP-4 and TIMP-2 in pro-MMP-2 activation by MT1-MMP. Biochem. Biophys. Res. Commun. 281, 126-130.

Hoshino, D., Kirkbride, K.C., Costello, K., Clark, E.S., Sinha, S., Grega-Larson, N., Tyska, M.J., Weaver, A.M., 2013. Exosome secretion is enhanced by invadopodia and drives invasive behavior. Cell Rep. 5, 1159-1168.

Kai, H.S., Butler, G.S., Morrison, C.J., King, A.E., Pelman, G.R., Overall, C.M., 2002. Utilization of a novel recombinant myoglobin fusion protein expression system to characterize the tissue inhibitor of metalloproteinase (TIMP)-4 and TIMP-2 C-terminal domain and tails by mutagenesis. The importance of acidic residues in binding the MMP-2 hemopexin C-domain. J. Biol. Chem. 277, 48696-48707.

Kammerer, R.A., Kostrewa, D., Progias, P., Honnappa, S., Avila, D., Lustig, A., Winkler, F.K., Pieters, J., Steinmetz, M.O., 2005. A conserved trimerization motif controls the topology of short coiled coils. PNAS 102, 13891-13896.

Kesel, A.B., Junge, M.M., Nachtigall, W., 1999. Einführung in Die Angewandte Statistik Für Biowissenschaftler. Birkhäuser, Basel, Boston, Berlin.

Kimura, T., Taniguchi, S., Niki, I., 2010. Actin assembly controlled by GDP-Rab27a is essential for endocytosis of the insulin secretory membrane. Arch. Biochem. Biophys. 496, 33-37.

Laemmli, U.K., 1970. Cleavage of structural proteins during the assembly of the head of bacteriophage T4. Nature 227, 680-685.

Lee, M.H., Maskos, K., Knauper, V., Dodds, P., Murphy, G., 2002. Mapping and char acterization of the functional epitopes of tissue inhibitor of metalloproteinases (TIMP)-3 using TIMP-1 as the scaffold: a new frontier in TIMP engineering. Protein Sci. 11, 2493-2503.

Lee, S., Desai, K.K., Iczkowski, K.A., Newcomer, R.G., Wu, K.J., Zhao, Y.-G., Tan, W.W., Roycik, M.D., Sang, Q.-X.A., 2006. Coordinated peak expression of MMP-26 and TIMP-4 in preinvasive human prostate tumor. Cell Res. 16, 750-758.

Luan, S.L., Boulanger, E., Ye, H., Chanudet, E., Johnson, N., Hamoudi, R.A., Bacon, C.M., Liu, H., Huang, Y., Said, J., Chu, P., Clemen, C.S., Cesarman, E., Chadburn, A., Isaacson, P.G., Du, M.Q., 2010. Primary effusion lymphoma: genomic profiling revealed amplification of SELPLG and CORO1C encoding for proteins important for cell migration. J. Pathol. 222, 166-179.

Lukaszewicz-Zajac, M., Mroczko, B., Kornhuber, J., Lewczuk, P., 2014. Matrix metalloproteinases (MMPs) and their tissue inhibitors (TIMPs) in the tumors of central nervous system (CNS). J. Neural Transm. 121, 469-477.

Maire, C.L., Ligon, K.L., 2011. Glioma models: new GEMMs add "class" with genomic and expression correlations. Cancer Cell 19, 295-297.

McArdle, B., Hofmann, A., 2008. Coronin structure and implications. In: Clemen, C.S., Eichinger, L., Rybakin, V. (Eds.), The Coronin Family of Proteins. Landes Bioscience \& Springer p. Available from: http://www.ncbi.nlm.nih.gov/books/NBK6058/.

Melendez-Zajgla, J., Del Pozo, L., Ceballos, G., Maldonado, V., 2008. Tissue inhibitor of metalloproteinases-4. The road less traveled. Mol. Cancer 7, 85.

Mondol, A.S., Tonks, N.K., Kamata, T., 2014. Nox4 redox regulation of PTP1B contributes to the proliferation and migration of glioblastoma cells by modulating tyrosine phosphorylation of coronin-1C. Free Radic. Biol. Med. 67, 285-291.

Morgan, R.O., Fernandez, M.P., 2008. Molecular phylogeny and evolution of the coronin Gene family. In: Clemen, C.S., Eichinger, L., Rybakin, V. (Eds.), The Coronin Family of Proteins. Landes Bioscience \& Springer p. Available from: http://www.ncbi.nlm. nih.gov/books/NBK6377/.

Noegel, A.A., Blau-Wasser, R., Sultana, H., Muller, R., Israel, L., Schleicher, M., Patel, H., Weijer, C.J., 2004. The cyclase-associated protein CAP as regulator of cell polarity and cAMP signaling in Dictyostelium. Mol. Biol. Cell 15, 934-945.

Pruefer, F., Vazquez-Santillan, K., Munoz-Galindo, L., Cruz-Colin, J.L., Maldonado, V., Melendez-Zajgla, J., 2016. TIMP4 modulates ER-alpha signalling in MCF7 breast cancer cells. Folia Biol. (Praha) 62, 75-81.

Redzic, J.S., Ung, T.H., Graner, M.W., 2014. Glioblastoma extracellular vesicles: reservoirs of potential biomarkers. Pers. Med. 7, 65-77.

Ren, G.P., Tian, Q.M.D., An, Y.M.D., Feng, B.P., Lu, Y.P., Liang, J.P., Li, K.P., Shang, Y.P., Nie, Y.P., Wang, X.P., Fan, D.P., 2012. Coronin 3 promotes gastric cancer metastasis via the up-regulation of MMP-9 and cathepsin K. Mol. Cancer 11, 67.

Roadcap, D.W., Clemen, C.S., Bear, J.E., 2008. The role of mammalian coronins in development and disease. In: Clemen, C.S., Eichinger, L., Rybakin, V. (Eds.), The Coronin Family of Proteins. Landes Bioscience \& Springer p. Available from: http:// www.ncbi.nlm.nih.gov/books/NBK6528/.

Rorive, S., Lopez, X.M., Maris, C., Trepant, A.L., Sauvage, S., Sadeghi, N., Roland, I., Decaestecker, C., Salmon, I., 2010. TIMP-4 and CD63: new prognostic biomarkers in human astrocytomas. Mod. Pathol. 23, 1418-1428.

Rosentreter, A., Hofmann, A., Xavier, C.P., Stumpf, M., Noegel, A.A., Clemen, C.S., 2007. Coronin 3 involvement in F-actin-dependent processes at the cell cortex. Exp. Cell Res. 313, 878-895.

Rybakin, V., Clemen, C.S., 2005. Coronin proteins as multifunctional regulators of the cytoskeleton and membrane trafficking. Bioessays 27, 625-632.

Sakurai-Yageta, M., Recchi, C., Le Dez, G., Sibarita, J.-B., Daviet, L., Camonis, J., D'SouzaSchorey, C., Chavrier, P., 2008. The interaction of IQGAP1 with the exocyst complex is required for tumor cell invasion downstream of Cdc42 and RhoA. J. Cell Biol. 181, 985-998.

Samarin, S.N., Koch, S., Ivanov, A.I., Parkos, C.A., Nusrat, A., 2010. Coronin 1C negatively regulates cell-matrix adhesion and motility of intestinal epithelial cells. Biochem. Biophys. Res. Commun. 391, 394-400.

Seiki, M., Koshikawa, N., Yana, I., 2003a. Role of pericellular proteolysis by membranetype 1 matrix metalloproteinase in cancer invasion and angiogenesis. Cancer Metastasis Rev. 22, 129-143.

Seiki, M., Mori, H., Kajita, M., Uekita, T., Itoh, Y., 2003b. Membrane-type 1 matrix metalloproteinase and cell migration. Biochem. Soc. Symp. 253-262.

Shields, J.M., Thomas, N.E., Cregger, M., Berger, A.J., Leslie, M., Torrice, C., Hao, H., Penland, S., Arbiser, J., Scott, G., Zhou, T., Bar-Eli, M., Bear, J.E., Der, C.J., Kaufmann, W.K., Rimm, D.L., Sharpless, N.E., 2007. Lack of extracellular signalregulated kinase mitogen-activated protein kinase signaling shows a new type of melanoma. Cancer Res. 67, 1502-1512.

Shin, J.B., Krey, J.F., Hassan, A., Metlagel, Z., Tauscher, A.N., Pagana, J.M., Sherman, N.E., Jeffery, E.D., Spinelli, K.J., Zhao, H., Wilmarth, P.A., Choi, D., David, L.L., Auer, M., Barr-Gillespie, P.G., 2013a. Molecular architecture of the chick vestibular hair bundle. Nat. Neurosci. 16, 365-374.

Shin, S.J., Smith, J.A., Rezniczek, G.A., Pan, S., Chen, R., Brentnall, T.A., Wiche, G., Kelly, K.A., 2013b. Unexpected gain of function for the scaffolding protein plectin due to mislocalization in pancreatic cancer. Proc. Natl. Acad. Sci. U. S. A. 110, 19414-19419.

Smith, T.F., 2008. Diversity of WD-repeat proteins. In: Clemen, C.S., Eichinger, L., Rybakin, V. (Eds.), The Coronin Family of Proteins. Landes Bioscience \& Springer p. Available from: http://www.ncbi.nlm.nih.gov/books/NBK6426/.

Spoerl, Z., Stumpf, M., Noegel, A.A., Hasse, A., 2002. Oligomerization, F-actin interaction, and membrane association of the ubiquitous mammalian coronin 3 are mediated by its carboxyl terminus. J. Biol. Chem. 277, 48858-48867.

Steffen, A., Le Dez, G., Poincloux, R., Recchi, C., Nassoy, P., Rottner, K., Galli, T., Chavrier, P., 2008. MT1-MMP-dependent invasion is regulated by TI-VAMP/VAMP7. Curr. Biol. 18, 926-931.

Stetler-Stevenson, W.G., 2008. Tissue inhibitors of metalloproteinases in cell signaling: metalloproteinase-independent biological activities. Sci. Signal. 1 re6.

Testa, G., Schaft, J., van der Hoeven, F., Glaser, S., Anastassiadis, K., Zhang, Y., Hermann, T., Stremmel, W., Stewart, A.F., 2004. A reliable lacZ expression reporter cassette for multipurpose, knockout-first alleles. Genesis 38, 151-158.

Thal, D., Xavier, C.P., Rosentreter, A., Linder, S., Friedrichs, B., Waha, A., Pietsch, T., Stumpf, M., Noegel, A.A., Clemen, C.S., 2008. Expression of coronin-3 (coronin-1C) in diffuse gliomas is related to malignancy. J. Pathol. 214, 415-424.

Towbin, H., Staehelin, T., Gordon, J., 1979. Electrophoretic transfer of proteins from polyacrylamide gels to nitrocellulose sheets: procedure and some applications. Proc. Natl. Acad. Sci. U. S. A. 76, 4350-4354.

Williams, K.C., Coppolino, M.G., 2011. Phosphorylation of membrane type 1-matrix metalloproteinase (MT1-MMP) and its vesicle-associated membrane protein 7 (VAMP7)-dependent trafficking facilitate cell invasion and migration. J. Biol. Chem. 286, 43405-43416.

Williamson, R.C., Cowell, C.A., Hammond, C.L., Bergen, D.J., Roper, J.A., Feng, Y., Rendall, T.C., Race, P.R., Bass, M.D., 2014. Coronin-1C and RCC2 guide mesenchymal migration by trafficking Rac1 and controlling GEF exposure. J. Cell. Sci. 127, 4292-4307.

Williamson, R.C., Cowell, C.A., Reville, T., Roper, J.A., Rendall, T.C., Bass, M.D., 2015. Coronin-1C protein and caveolin protein provide constitutive and inducible mechanisms of Rac1 protein trafficking. J. Biol. Chem. 290, 15437-15449.

Wu, L., Peng, C.W., Hou, J.X., Zhang, Y.H., Chen, C., Chen, L.D., Li, Y., 2010. Coronin-1C is a novel biomarker for hepatocellular carcinoma invasive progression identified by proteomics analysis and clinical validation. J. Exp. Clin. Cancer Res. 29, 17.

Xavier, C.-P., Eichinger, L., Fernandez, M.P., Morgan, R.O., Clemen, C.S., 2008 Evolutionary and functional diversity of coronin proteins. In: Clemen, C.S., Eichinger, L., Rybakin, V. (Eds.), The Coronin Family of Proteins. Landes Bioscience \& Springer p. Available from: http://www.ncbi.nlm.nih.gov/books/NBK6170/.

Xavier, C.P., Rastetter, R.H., Blomacher, M., Stumpf, M., Himmel, M., Morgan, R.O., Fernandez, M.P., Wang, C., Osman, A., Miyata, Y., Gjerset, R.A., Eichinger, L., Hofmann, A., Linder, S., Noegel, A.A., Clemen, C.S., 2012. Phosphorylation of CRN2 by CK2 regulates F-actin and Arp2/3 interaction and inhibits cell migration. Sci. Rep. $2,241$. 
Xavier, C.P., Rastetter, R.H., Stumpf, M., Rosentreter, A., Muller, R., Reimann, J., Cornfine, S., Linder, S., van Vliet, V., Hofmann, A., Morgan, R.O., Fernandez, M.P. Schroder, R., Noegel, A.A., Clemen, C.S., 2009. Structural and functional diversity of novel coronin 1C (CRN2) isoforms in muscle. J. Mol. Biol. 393, 287-299.

Yu, S.-p., Yang, X.-j., Zhang, B., Ming, H.-l., Chen, C., Ren, B.-c., Liu, Z.-f., Liu, B., 2011. Enhanced invasion in vitro and the distribution patterns in vivo of CD133 + glioma stem cells. Chin. Med. J. (Engl). 124, 2599-2604.
Zhao, Y.-G., Xiao, A.-Z., Park, H.I., Newcomer, R.G., Yan, M., Man, Y.-G., Heffelfinger, S.C., Sang, Q.-X.A., 2004. Endometase/matrilysin-2 in human breast ductal carcinoma in situ and its inhibition by tissue inhibitors of metalloproteinases- 2 and -4: a putative role in the initiation of breast cancer invasion. Cancer Res. 64, 590-598. Ziemann, A., Hess, S., Bhuwania, R., Linder, S., Kloppenburg, P., Noegel, A.A., Clemen,

C.S., 2013. CRN2 enhances the invasiveness of glioblastoma cells. Neurooncology 15, 548-561. 